\title{
TRANSFORMACIONES EN EL ROL DEL ESTADO. LA CONCESIÓN DE REDES VIALES EN ARG ENTINA
}

\author{
Valeria Serafinoff \\ Centro de Estudios de Estado y Sociedad, \\ Argentina
}

\section{Resumen}

El objetivo general del presente trabajo es estudiar las características de la regulación de redes viales concesionadas en Argentina durante el período comprendido entre los años 1989-2006, considerando dos modelos de regulación: el primero, iniciado en 1989, y el segundo, en 2003.

El artículo plantea que la concesión y/o privatización de bienes o servicios públicos no puede significar el abandono de las responsabilidades por parte del Estado, por lo que deben realizarse en un marco regulado. Además, sugiere que la efectividad del programa de concesiones se asocia directamente con las características del proceso privatizador y que el fortalecimiento de las capacidades institucionales del organismo contralor es insuficiente para revertir las características de un modelo de concesión, como el argentino, que debido a la inestabilidad e incertidumbre, beneficia a un grupo específico de actores.

Palabras Claves: Estado Regulador, Obras Públicas, Concesión de Redes Viales, Argentina

\section{Abstact}

The general objective of this paper is to study the characteristics of the regulatory framework for the road networks concession system in Argentina during the 1989-2006 period, considering two regulation models, which begun in 1989 and 2003 respectively.

The article argues that the concession and / or privatization of public goods or services can not mean abandoning the nation state responsibilities, which means those concession programs must operate within a regulatory framework. Additionally, it suggests that the effectiveness of the concession program it directly associated with the privatisation process' characteristics and that strengthening institutional capacities of the comptroller agency is insufficient to overturn the features of a concessions model, such as the Argentinean, which, as a result of uncertainty and instability, benefits to specific groups of players.

Keywords: Regulatory State, Public Works, Road Networks Concession System, Argentina 


\section{Introducción}

En la década del '90 se produce en Argentina un proceso de reformas económicas que establece, como pieza fundamental, la transformación del rol estatal. Dichas reformas se expresaron, fundamentalmente, a través de la transferencia a terceros de la responsabilidad de producir bienes y servicios, mediante la privatización/ concesión, descentralización, tercerización y desregulación de actividades económicas.

En este contexto, y dentro de la primera etapa privatizadora, se realizaron las concesiones de redes viales. La celeridad del proceso privatizador y la ausencia de una ley marco que regulara la transferencia y posterior prestación del servicio, convirtieron a la concesión de las rutas argentinas en uno de los procesos más cuestionados del país. Por ello, avanzar en el conocimiento de las características del sector y las constantes renegociaciones que enmarcaron las relaciones entre los principales actores, puede convertirse en un elemento relevante para analizar la debilidad estatal.

El objetivo general del presente trabajo es estudiar las características de la regulación de redes viales concesionadas en Argentina durante el período comprendido entre los años 19892006, considerando dos modelos de regulación de concesiones viales: el primero, iniciado en 1989, y el segundo, en 2003, luego del epicentro de la crisis y en la primera etapa de un gobierno que planteaba, al menos discursivamente, la necesidad de revisar el proceso de reformas del estado de la década del '90. La perspectiva adoptada es la del análisis de políticas públicas.

Al considerar, específicamente, la concesión de redes viales, Bousquet y Fayard (2001:3) definen a las concesiones como un sistema en el cual la autoridad pública garantiza a una organización (sea privada o semipública) derechos específicos para construir, reparar, mantener y operar un tipo particular de infraestructura por un período determinado. Estos autores sostienen que el contrato de concesión es el que establece los términos en los cuales la autoridad pública da a una empresa la responsabilidad de cubrir los costos de las inversiones necesarias para brindar un servicio, operando bajo sus propios costos y riesgos. Otro elemento a considerar se vincula con el tipo de remuneración que puede darse a los concesionarios, ya sea que el pago del peaje lo realicen los usuarios o la autoridad pública (shadow toll). A estos dos tipos que reconocen Bousquet y Fayard (2001) sería posible agregar un tercero, el subsidiado, en el cual se combinan los dos primeros, ya que al pago de peaje por el usuario del servicio se suma el aporte estatal (establecido, por ejemplo, en función del tránsito existente). Así, dos aspectos aparecen vinculados con la concesión: 1) la transferencia del riesgo, de la autoridad pública a una prestadora y; 2) la noción de globalidad contractual, involucrando todos los aspectos vinculados a la operatoria de la infraestructura.

A pesar del carácter de bien público que da el Código Civil argentino a los caminos y rutas, desde la economía se presenta un debate a fin de precisar qué tipo de bien representa cada 
uno de los caminos y evaluar así la posibilidad de optar por distintos mecanismos para su construcción, mantenimiento y/o gestión. La clasificación de los tipos de caminos es una cuestión central para evaluar aquellos que podrían ser administrados por consorcios privados. No obstante, existen otros aspectos relevantes a considerar para establecer los caminos que pueden ser objeto de concesión ${ }^{1}$ : la existencia de un camino alternativo de libre acceso ${ }^{2}$; la posibilidad de que se establezcan subvenciones cruzadas y la necesidad de integrar carreteras. La concesión conjunta intenta incrementar la viabilidad financiera de los proyectos.

La adjudicación de los caminos se realiza, por lo general, a través de un proceso de licitación. Se espera que, a fin de lograr transparencia y estabilidad, el contrato de concesión establezca indicadores claros para medir la calidad del servicio brindado, el cumplimiento de los compromisos de inversión y los mecanismos de fijación de tarifas así como los momentos de revisión.

A lo largo del trabajo se irán presentando una serie de proposiciones generales surgidas del análisis de los hechos relevados y de la identificación de aspectos sistemáticos y no sistemáticos, las cuales serán retomadas en la conclusión. Sin embargo, hay tres presunciones básicas de las que se parte:

- La concesión y/o privatización de bienes o servicios públicos no puede significar el abandono de las responsabilidades por parte del Estado, por lo que deben realizarse en un marco regulado. El proceso no es meramente técnico y expresa niveles de conflictividad entre distintos actores sociales. Por tal motivo, en los países donde el Estado, históricamente, ha sido considerado como un actor débil frente a los intereses privados, se requiere necesariamente de un fortalecimiento de las instituciones.

- La efectividad del programa de concesiones se asocia directamente con las características del proceso privatizador pues, si inicialmente no se toman ciertas previsiones, entre otras, tener un conocimiento acabado de lo que se concesiona; garantizar la competencia y transparencia del proceso privatizador; establecer claras y sencillas reglas de juego, la incertidumbre de los actores aumenta y con ello su interés por maximizar sus beneficios individuales en el corto plazo.

- El fortalecimiento de las capacidades institucionales del organismo contralor es insuficiente para revertir las características de un modelo de regulación que beneficia a un grupo de actores, donde la incertidumbre e inestabilidad normativa actúan reforzando dicha preferencia.

La siguiente sección se refiere a los antecedentes de constante crisis por las que ha atravesado el sector en Argentina. Posteriormente, se analizan los aspectos que dieron origen

1 En base a lo planteado por Estache; Romero y Strong (2000).

2 Estache; Romero y Strong (2000) sugieren que la evidencia muestra que los niveles de tráfico en la mayoría de los países en desarrollo no permiten la existencia de carreteras alternativas porque reducen las previsiones realizadas inicialmente. 
al surgimiento de la cuestión en la agenda pública las dos concesiones de rutas nacionales con una intención comparativa. A continuación, se establecen los lineamientos que definen las características salientes del modelo regulador configurado, caracterizado por la alta inestabilidad y su funcionalidad a ciertos intereses. En la sección que sigue, se hace foco en los déficit de capacidad institucional del organismo de control con el fin de analizar el impacto que tiene el diseño de las instituciones de regulación y control sobre los resultados de la concesión de redes viales, privilegiando el análisis de los efectos de los desequilibrios entre los actores con la dinámica de funcionamiento de los organismos de control. Finalmente, se presentan las conclusiones del estudio.

\section{La conformación del sector vial: un sector en continua crisis}

La inversión en infraestructura vial en Argentina, que tuvo un desarrollo tardío respecto del sistema ferroviario, fue históricamente financiada por el Estado a través de fondos específicos provenientes básicamente del impuesto a los combustibles. Recién a fines del siglo XIX y comienzos del XX aparece la necesidad de mejorar la red vial y hacia 1932 comienza a organizarse la actividad vial con características que persistirían hasta la concesión de la red en 1990. Por ejemplo, en ese año se crea la Dirección Nacional de Vialidad (DNV), como organismo autárquico, encargado de proyectar, construir y conservar la red vial nacional y se conforma un Fondo Nacional de Vialidad, a partir de impuestos de suma fija sobre los combustibles y lubricantes. Por 30 años se adoptaron distintas medidas que, contradictoriamente, se orientaron a incorporar nuevos bienes al Fondo Vial (v.g. cubiertas), pero también a reducir la participación global del sistema en los fondos recaudados (v.g. fondo de energía).

Como justificación de esas contradictorias políticas, desde el Estado se señalaba, cada vez con mayor insistencia, el constante déficit de obras existente, el cual se encontraba vinculado con la paulatina disminución de la inversión en obra pública, el creciente y, en algunos casos, alarmante deterioro en la infraestructura y la focalización de los recursos en la reparación de los caminos destruidos, lo cual se señalaba, llevaría al colapso del sistema vial argentino. Hacia la década del ' 60 , esa situación se veía agravada por un aumento no previsto del tráfico de cargas y el creciente uso del automotor como medio de transporte. Por ello, en noviembre de 1967, se promulgó una ley (17.520) que facultaba al Poder Ejecutivo a construir obras mediante su concesión a particulares, sociedades mixtas o entes públicos, con una consecuente aplicación de tarifas de peaje a los usuarios de dichas obras ${ }^{3}$. Además de la facultad de realizar obras a través de la aplicación de tarifas de peaje, la ley, elaborada en el gobierno de Onganía, legisló

3 Las concesiones por peaje que se realizaron a partir de esta norma fueron para la construcción de obras totalmente nuevas. En tal sentido, son relevantes las primeras experiencias de capital privado con cobro de peaje de la AU1, AU6 y Autopista 9 de Julio de Capital Federal; Camino del Buen Ayre; Autopista Bs. As.- La Plata. También el cobro de peaje se realizaba en caminos construidos por el Estado. 
sobre el carácter de las concesiones (oneroso, gratuita, subvencionada); definió los procedimientos para otorgar obra pública e incrementó las atribuciones de la Secretaría de Obra Pública. A pesar de introducir cambios profundos, esta ley no tuvo grandes efectos, al menos hasta la década del ' 90 , pues la mayoría de las obras públicas continuaron construyéndose mediante el sistema tradicional. Continuaría, entonces, la tendencia a la reducción de fondos para la construcción y mantenimiento de los caminos.

\section{Las reformas neoliberales y la creación de un primer modelo de concesión- regulación}

La política de concesiones viales fue adoptada en Argentina a principio, de la década del '90, en la cual se profundiza un proceso de reformas económicas, que pueden considerarse como parte de una orientación de política económica iniciada en la década del '70. En 1989 la crisis económica constituía el principal problema de la agenda pública. El pronunciado estancamiento padecido desde mediados de los setenta; la hiperinflación; el déficit fiscal crónico; la baja capacidad de ahorro nacional; el significativo atraso en los pagos de la deuda y el consecuente incremento del endeudamiento externo; así como los bajos coeficientes de inversión que, entre otros, derivaron en la insatisfacción ante el funcionamiento de las empresas públicas y la extendida crítica al gigantismo estatal, originaron un sentimiento común en la opinión pública favorable a una substancial reorientación del modelo económico. Si bien el presente estudio asigna un rol central al análisis del contexto en el que se toma la decisión de concesionar las rutas ello no implica considerar, como muchas visiones plantean, que dadas las condiciones macroeconómicas y sociales argentinas no era posible adoptar una alternativa distinta a la privatizadora o un modelo de concesiones viales diferente al que se configuró en 1989. Por el contrario, la revisión del contexto en el que se definió la política pública considerada debería poder demostrar que los actores, fundamentalmente, los gubernamentales, forzaron una definición de la problemática que, tal como estaba planteada, no dejaba espacio para otra política. No obstante, una definición distinta del problema inicial, podría haber generado una alternativa de resolución diferente, seguramente, menos radicalizada.

Las tendencias regionales, impulsadas por el Consenso de Washington, adquirieron en Argentina características diferenciales. El gobierno de Menem (1989-1999), apenas asumido, adoptó la estrategia de actuar con rapidez y recurrió al factor sorpresa con el fin de disminuir las probabilidades de formación de frentes de resistencia a la decisión presidencial. Al interior del Estado existió un amplio consenso en torno a la solución vía privatizaciones, la cual sólo fue cuestionada por algunos miembros de los partidos de la izquierda argentina, quienes no tenían un poder real como para torcer el rumbo de la política nacional. El horizonte reformista hizo que el nuevo gobierno tomara distancia de su coalición electoral y, en particular, de su partido, de forma de ganar autonomía para conformar una coalición más consistente con el 
rumbo adoptado. Así, Menem se alió con la elite económica argentina y los partidos políticos de centro derecha (Unión de Centro Democrático y partidos provinciales con representantes en el Congreso), mientras incorporó outsiders ${ }^{4}$ a la política y economistas de la ortodoxia liberal, así como también siguió, al pie de la letra, los principios del Consenso de Washington, por lo que se aseguró el apoyo de los organismos internacionales de crédito. Por su parte, la segunda fuerza partidaria (la Unión Cívica Radical), no encontraba la forma de organizarse como oposición luego de su salida anticipada del gobierno. Las desavenencias internas y la escasa credibilidad social confluyeron en la pasividad opositora frente a las transformaciones que se estaban produciendo y derivaron en el acuerdo con el justicialismo para apoyar los principales proyectos de ley enviados por el Ejecutivo al Congreso. Asimismo, no se observaron manifestaciones contrarias de parte de los sindicatos ni de los burócratas.

La reconversión neoliberal diagnosticó que la crisis económica era atribuible al fracaso de un modelo de organización social fundado en una matriz estado-céntrica que había facilitado un intervencionismo excesivo del estado, la asunción de roles no pertinentes y la conducta predatoria de quienes controlaban su aparato (Oszlak, 1999). El Estado fue demonizado y frente a ello la única alternativa era despojarse de él. A lo largo de todo el período analizado, el Estado no pudo, probablemente, ni siquiera intentó, establecerse como un actor neutral que pudiera mediar en la relación entre los actores. Por el contrario, podría afirmarse que el Estado fue capturado por los intereses de un sector de la sociedad, que de esa forma logró imponer sus principios y demás mecanismos articuladores.

Tal como se señaló anteriormente, en materia vial existió en Argentina un histórico déficit en la construcción y mantenimiento de los caminos. Así como también una errática respuesta estatal ya que las distintas decisiones tomadas no lograron revertir la tendencia de pocas inversiones en el sector.

La crisis fiscal de la década del ' 80 arrojó como resultado que la infraestructura vial se deteriorara aún más. El pronóstico de un colapso del sistema vial sino se encontraban fuentes alternativas de financiamiento resurgía cada vez con mayor ímpetu. Hacia fines de la década del '80 sólo un 30\% de caminos pavimentados estaban en buen estado, mientras el deterioro anual de los caminos alcanzaba el 10\% y el Estado sólo era capaz de repavimentar un 3,5\% de la red total (Gerchunoff y Canovas, 1994). En ese contexto, en agosto de 1989 se promulgaron las leyes de Emergencia Administrativa y Reforma del Estado y de Emergencia Económica, las cuales, formalmente, establecieron una ruptura el modelo económico preexistente. La primera

4 Se hace referencia a la incorporación de artistas, empresarios y deportistas exitosos a la vida política. Personas con un gran reconocimiento social que se presentan como candidatos para ocupar cargos políticos (v.g. Palito Ortega, cantante que fue gobernador de Tucumán; Carlos Reuteman, ex corredor de Fórmula 1 que fue gobernador de Santa Fe y Daniel Scioli, corredor de Motonáutica, fue Diputado Nacional y, actualmente, es Vicepresidente de la Nación). 
de las normas declaró la emergencia en la prestación de servicios públicos, en general, y de la red vial, en particular, además de poner fin a la existencia del Fondo Vial. Por su parte, la ley de Reforma del Estado introdujo modificaciones a ley de peajes, permitiendo la concesión rutas nacionales por peaje para su mantenimiento. Es decir, se permitió a partir de los cambios normativos introducidos la explotación privada de obras realizadas a través de fondos públicos (sin necesidad de que se construyan nuevos tramos). Se esperaba que la tarifa de peaje, compensara la ejecución, modificación, ampliación, administración, reparación, conservación o mantenimiento de la obra existente y la ejecución, explotación y mantenimiento de la obra nueva. En tanto, se establecía que las inversiones a realizarse no debían ser financiadas "con recursos de crédito a obtenerse por el Estado o por el concesionario con la garantía de aquel"5. Se estableció el programa de reconversión vial y se pautó la reorganización de la Dirección Nacional de Vialidad (DNV), uno de los organismos intervenidos. La entidad autárquica se reorganizó como agente responsable de la aplicación de la política vial del país e inició un programa de "Reconversión Vial" basado en la descentralización, desregulación y privatización de la red vial de caminos. La red vial nacional fue reordenada teniendo en cuenta cuestiones tales como cantidad y tipo de tránsito y estado de la calzada en los diferentes tramos. La reestructuración implicó la definición de tramos que luego serían entregados a concesionarios privados: a) utilizando el criterio internacional que considera que el financiamiento del sistema de peaje resulta factible si existe un Tránsito Medio Diario Anual (TMDA) superior a los 2.000/2.500 vehículos/día) 6 ; b) la realización de concesiones totales o parciales para reparación y mantenimiento de la red troncal nacional y, por último, c) la transferencia, mediante convenio, a jurisdicciones provinciales o municipales de rutas nacionales de interés provincial.

Por medio de una Resolución del Ministerio de Obras y Servicios Públicos se aprobó el pliego de condiciones generales para la Licitación y las condiciones particulares para la concesión de obras viales, así como el cronograma del llamado a licitación. Se estableció también que las concesiones no contaran con garantías de transito mínimo ni de ningún otro tipo. Es decir, legalmente se constituyó como un negocio de riesgo.

A pesar de tratarse de una licitación internacional, sólo participaron de dicho proceso empresas argentinas. Algunos factores que pueden explicar la ausencia de firmas extranjeras son la exigencia de que las firmas estuvieran inscriptas en el Registro Nacional de Constructores, aunque como señala Fiel(1998) también debe considerarse que no existe constancia de que

5 Este principio fue abandonado a través de las renegociaciones, la incorporación de la cláusula indemnizatoria y los subsidios del Estado, instrumentos que terminaron reduciendo el riesgo y garantizando una alta rentabilidad a las empresas.

6 Según Pressman (s/f) las rutas no concesionadas se constituyeron como proveedores de tránsito para los corredores concesionados 
se haya realizado un llamado fuera de Argentina. El proceso licitatorio estuvo lejos de recrear una competencia entre empresas oferentes de probada capacidad en la materia y los pliegos fueron elaborados de manera conjunta con representantes de varias de las firmas que finalmente resultaron adjudicatarias ${ }^{7}$. Varias fuentes consultadas, señalaron incluso que representantes de los principales grupos constructores participaron de la redacción de los pliegos ${ }^{8}$. La amplia discrecionalidad del proceso licitatorio es evidente en la fijación de los coeficientes utilizados para la ponderación de los criterios de relevancia, los cuales se establecieron con posterioridad a la apertura de los sobres con las ofertas (Azpiazu; Pesce, 2003). Finalmente, la simultaneidad de las licitaciones facilitó el comportamiento colusivo de los consorcios a través de un mecanismo de "reparto" de los corredores ofertados (Rima, Sanchez y Yánez, 1997; Azpiazu y Pesce, 2003).

En septiembre de 1990, a través de un decreto, se concedieron unos $9.600 \mathrm{Kms}$. -organizados en 19 corredores $^{9}$-de red pavimentada, un $30 \%$ de las rutas nacionales pavimentadas, que concentraba más de la mitad del tránsito, además de conectar las principales áreas urbanas y rurales del país, así como la mayor parte de los puertos y puentes internacionales. Entre las condiciones mínimas impuestas para presentarse al proceso licitatorio sobresalen la mejora del Índice de Estado de Caminos $^{10}$ adjudicados y la realización de tareas mínimas al cobro de peaje. En tanto, que los corredores fueron adjudicados a los grupos empresarios tomándose como variable determinante la cotización del canon ${ }^{11}$.

Los corredores viales nacionales fueron adjudicados a 13 concesionarios conformados por 30 empresas adjudicatarias, además de la unión de empresas transitorias que se hizo cargo del corredor 6 . Es de destacar que las empresas adjudicatarias fueron las antiguas contratistas del Estado a través de la DNV y que tres holdings se adjudicaron más de la mitad de la longitud de la red vial argentina concesionada, situación que indica la concentración empresarial ${ }^{12}$.

Los contratos establecieron que el plazo de la concesión se extendería por doce años. Se considera que cuanto más corto sea el mismo, es mayor el potencial de introducir los mecanismos de competencia por el mercado. Sin embargo, un plazo muy breve podría generar desincentivos a la inversión (Estache; de Rus, 2003).

7 Incluso dos diputados del Partido Justicialista presentaron una denuncia que indicaba que en las licitaciones de CV actuaban personas que mantenían relación de dependencia profesional con empresas que participaban de las licitaciones (subsecretarios y asesores de Obras Públicas que hasta semanas antes de realizar el llamado se desempeñaban en empresas como SIDECO y SEMACAR, las cuales luego resultaron adjudicatarias de corredores.

8 Incluso esto fue señalado en una querella presentada en 2003 por la Oficina Anticorrupción.

9 No se presentaron ofertas para el corredor 19.

10 Este índice establece una fórmula a partir de la cual se evalúa el estado de los caminos y su transitabilidad. 11 El corredor 15, adjudicado, por el mismo decreto, a la Concesionaria Vial del Sur, COVISUR SA, no se considerara en este trabajo puesto que el mismo fue posteriormente transferido a la Provincia de Buenos Aires. Por ello, en lo sucesivo las referencias serán a la adjudicación de 18 corredores viales.

12 En tal sentido, debe considerarse que Benito Roggio SA se adjudicó -a través de distintos consorcios- unos 2.500 Kms. de la red concesionada, Techint, 1205 Kms., y Sideco Americana, 1169 Kms. 
Distintos autores (Gómez-Lobo; Hinojosa, 1999; Rufian Lizana, 2002; Estache; de Rus, 2003) señalan la importancia de incluir en los contratos de concesión las reglas para la fijación de las tarifas y las inversiones a realizar. Asimismo, los contratos deberían clarificarse todos los aspectos técnicos de la regulación económica, el tipo de regulación a implementar y la posibilidad de diferenciar precios. En la experiencia argentina los contratos establecieron las tarifas y programas de inversión. Sin embargo, el desarrollo posterior de las concesiones viales, muestran que si bien la tarifa es un criterio importante no debe ser el único criterio a tener en cuenta. En este sentido, a través del análisis del caso argentino se observa que la ausencia de un estudio sistemático sobre las probabilidades de cumplir con las obras presentadas por los consorcios trae consecuencias irreparables puesto que, en cierta forma, actúa justificando la incertidumbre provocada por la inseguridad jurídica surgida de la necesidad de las constantes revisiones de reglas de juego. Así, las fallas regulatorias son más evidentes cuando el proceso privatizador no ha identificado las necesidades específicas de la infraestructura concesionada. En tal sentido, podemos afirmar que una menor diagramación y estudio de las condiciones iniciales y los riesgos existentes aumenta la asimetría entre el concesionario y el concedente en desmedro de la posición de los usuarios y la ciudadanía. Además estas condiciones se vuelven muy difíciles de revertir puesto que retroalimentan la vulnerabilidad estatal.

TABLA 1: Corredores Nacionales, modalidad de adjudicación y concesionario

\begin{tabular}{|c|c|c|c|c|c|c|c|c|}
\hline \multirow[t]{2}{*}{ CV } & \multirow[t]{2}{*}{ Rutas } & \multirow[t]{2}{*}{ Longitud } & \multirow[t]{2}{*}{ Modalidad } & \multirow{2}{*}{$\begin{array}{l}1^{\circ} \\
\text { Renegoc. }\end{array}$} & \multirow{2}{*}{$\begin{array}{l}2^{\circ} \\
\text { Renegoc. }\end{array}$} & \multirow[t]{2}{*}{ Concesionario } & \multicolumn{2}{|l|}{ Composición accionaria } \\
\hline & & & & & & & Empresa & $\%$ \\
\hline 1 & 3.252 & 665 & Onerosa & * & ${ }^{*}(1)$ & \multirow{2}{*}{ SEMACAR S.A. } & \begin{tabular}{|l} 
Dycasa \\
\end{tabular} & 55 \\
\hline 2 & 205 & 297 & Onerosa & * & $*(1)$ & & Perales Aguiar S.A. & 45 \\
\hline 3 & 7 & 507 & Onerosa & * & ${ }^{*}(1)$ & \multirow[t]{2}{*}{ CAMINOS DEL OESTE S.A. } & Techint S.A. & 99,9 \\
\hline 4 & 8.193 & 697 & Onerosa & * & ${ }^{*}(1)$ & & \multicolumn{2}{|l|}{ Santa Maria y Cía. S.A. } \\
\hline 5 & 7 & 421 & Onerosa & * & $*(1)$ & NUEVAS RUTAS S.A. & \multicolumn{2}{|l|}{ J.J.Chediak S.A.I.C.A. } \\
\hline \multirow{2}{*}{$\frac{6}{7}$} & 188 & 479 & Subven & * & ${ }^{*}(1)$ & COVICO S.A. & \multicolumn{2}{|l|}{ UTE (2) } \\
\hline & $9 \mathrm{~A}-012$ & 247 & Onerosa & * & $*(1)$ & \multirow{3}{*}{ SERVICIOS VIALES S.A. } & \multirow{3}{*}{\begin{tabular}{|l} 
Sideco Americana S.A. \\
SOCMAAmericana S.A. \\
Macri (Mauricio, Sandra \\
Gianfranco, Mariano,Florencia) \\
\end{tabular}} & \multirow{3}{*}{$\begin{array}{l}83,7 \\
3,6 \\
2,66 \\
c / u\end{array}$} \\
\hline 8 & 11.A009 & 693 & Onerosa & * & $*(1)$ & & & \\
\hline 9 & 33 & 298 & Onerosa & * & $*(1)$ & & & \\
\hline \multirow[t]{2}{*}{10} & \multirow[t]{2}{*}{9} & \multirow[t]{2}{*}{332} & \multirow[t]{2}{*}{ Onerosa } & \multirow[t]{2}{*}{ * } & \multirow[t]{2}{*}{$*(1)$} & \multirow[t]{2}{*}{ COVICENTRO S.A. } & \begin{tabular}{|l} 
Caminos Australes S.A. \\
$\mathrm{CCI}$ Concesiones S.A.
\end{tabular} & $\begin{array}{l}53,8 \\
35,5\end{array}$ \\
\hline & & & & & & & $\begin{array}{l}\text { Dragados y Obras Portuarias } \\
\text { Supercemento SAIC }\end{array}$ & $\begin{array}{l}5,38 \\
5,38\end{array}$ \\
\hline 11 & 34 & 640 & Onerosa & * & ${ }^{*}(1)$ & COVINORTE S.A. & Caminos Australes S.A. & 38,5 \\
\hline & & & & & & & \begin{tabular}{|l|} 
CCI Concesiones S.A. \\
Dragados y Obras Portuarias \\
\end{tabular} & $\begin{array}{l}38,5 \\
11,53\end{array}$ \\
\hline & & & & & & & Supercemento SAIC & 11,53 \\
\hline 12 & 9,34 & 481 & Onerosa & * & ${ }^{*}(1)$ & CONCANOR S.A. & Caminos Australes S.A. & 38,5 \\
\hline & & & & & & & CCI Concesiones S.A. & 38,5 \\
\hline & & & & & & & \begin{tabular}{|l|} 
Dragados y Obras Portuarias \\
\end{tabular} & 11,54 \\
\hline & & & & & & & Supercemento SAIC & 11,54 \\
\hline 13 & 12,16 & 946 & Onerosa & * & $*(1)$ & CONSORCIO VIRGEN DE ITATI SA & $\begin{array}{l}\text { Z Inversora S.A. } \\
\text { Chacofi S.A. }\end{array}$ & $\frac{25}{25}$ \\
\hline & & & & & & & \begin{tabular}{|l|} 
Palan S.A. \\
\end{tabular} & 20 \\
\hline & & & & & & & Dragados y Obras Portuarias & 15 \\
\hline & & & & & & & Supercemento SAIC & 15 \\
\hline 14 & 19 & 280 & Onerosa & * & $*(1)$ & RUTAS DEL VALLE S.A. & $\begin{array}{l}\text { Luciano S.A. } \\
\end{array}$ & 39,2 \\
\hline & & & & & & & Sycic S.A. & 36,3 \\
\hline & & & & & & & Compañia Oncrelur & 24,5 \\
\hline 15 & & 280 & Onerosa & $\begin{array}{l}\text { Transfe } \\
\text { Prov. d }\end{array}$ & $\begin{array}{l}\text { ido a la } \\
\text { Bs. As. }\end{array}$ & COVISUR S.A. & $\begin{array}{l}\text { Roggio SA (por medio de Rutas } \\
\text { Australes SA) DYCASA }\end{array}$ & \\
\hline 16 & 226 & 404 & Onerosa & 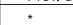 & *(1) & CAMINO DEL ABRASA & Coarco S.A. & 50 \\
\hline 16 & 226 & 404 & Unerosa & 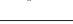 & (1) & & Equimac S.A. & 50 \\
\hline 17 & 5 & 540 & Onerosa & * & ${ }^{*}(1)$ & NUEVAS RUTAS S.A. & Chediak S.A. & 50 \\
\hline 18 & 12.193.14.13 & 626 & Onerosa & * & & CAMINOS DEL RIO URUGUAY S.A. & $\begin{array}{l}\text { Necon S.A. } \\
\text { Welbwers SA-Conevial SA-Babic }\end{array}$ & $\frac{50}{c S A}$ \\
\hline 10 & $5 . A 015.417$ & 626 & Onerosa & & (en 1996) & & Codi SA - Eaca SA-Parenti Mai & \\
\hline 20 & & 309 & Onerosa & * & $*(1)$ & & Caminos Australes SA & 57 \\
\hline 20 & AOO5 & 309 & Unerosa & & (I) & RED VIAL CENTRO S.A. & Romero Cammisa SA & 10,7 \\
\hline & & & & & & & Boetto y Buttigiengo SA & 10,7 \\
\hline & & & & & & & $\begin{array}{l}\text { Construcciones de Ingenieria } \\
\text { Alema SA }\end{array}$ & $\frac{10,7}{107}$ \\
\hline
\end{tabular}

Fuente: Elaboración propia en base a información surgida de los decretos de concesión, las Actas de Acuerdo de renegociaciones, los contratos de concesión vial y el Organismo de Control de Concesiones Viales (OCCOVI).

(1) Renegociado en 2001, finalizadas en octubre de 2003

(2) UTE compuesta por TECSA S.A, Noroeste Construcciones S.A, Néstor Guerechet S.A, I.C.F, Gikstein y Cia SACIAM, Estructuras SACICIF, Enrieto Dante, Empresa Constructra Delta SA, Coemyc SA, Bonfantti y Di Biasio SC, Bacigalupi y De Stefano SAICIA, Asfalsud SAIFIlyE. 


\subsection{La inestabilidad de los acuerdos}

El proceso de concesión, por lo general, se caracteriza por la transferencia del riesgo a un actor privado. En el momento de realizar las concesiones, a diferencia de lo que ocurrió en otras experiencias, no se habilitaron garantías que permitieran reducir dichos riesgos para los privados. Sin embargo, el Estado argentino ha resguardado los intereses de los concesionarios de rutas a través de mecanismos poco transparentes o garantías implícitas brindadas por las constantes y recurrentes renegociaciones.

Desde la firma de los contratos de concesión de las redes viales, se llevaron adelante numerosas modificaciones, llegando a desarrollarse tres procesos de renegociación, caracterizados todos ellos por la prolongación de etapas de incertidumbre, la contradicción de las medidas adoptadas y la sistemática revisión de las condiciones anteriormente acordadas.

Apenas transcurridos unos meses desde la concesión, se produce la primera renegociación, fundamentada en los fuertes reclamos sociales motivados por los altos costos en las tarifas básicas que - siguiendo la fórmula de indexación - habían aumentado más del $50 \%$ en cuatro meses, sin que se realizaran las obras acordadas y con las cabinas de peaje ubicadas captando el tráfico suburbano. Se señalaba que las características de la concesión resultaban lesivas para el interés general y garantizaban beneficios abusivos, perjudicando específicamente a las economías regionales y podrían resultar en un incremento general de precios. Entonces, surgía la necesidad de revisar el emplazamiento de los puestos de cobro de la tarifa.

Esta primera renegociación, que se dio en el marco de la promulgación de la ley de Convertibilidad (ley 23.928) y en la prohibición expresa de indexar precios, tarifas y toda actualización monetaria, arrojó como resultado que se extendiera el plazo de concesiones en un año, la reprogramación de compromisos de inversión, la eliminación del canon y un subsidio estatal, también se acordó el pago de una compensación indemnizatoria anual. Como contraparte se volvieron a localizar las cabinas de peaje y se fijó una nueva tarifa de peaje, aunque se estableció que la misma se fije mediante la aplicación de la tasa LIBOR ajustada en $20 \%$.

Las nuevas condiciones no generarían estabilidad ni serían muy duraderas. En agosto de 1993, cuando se debía realizar el primer ajuste en las tarifas, comenzaron nuevas luchas sobre los criterios. Una situación similar se reprodujo al año siguiente. Sin embargo, los cambios normativos sustentados, según las versiones oficiales, en la necesidad de reducir los costos de transporte en las rutas argentinas, evitando un aumento significativo de las tarifas, no generaron "daño" alguno a las empresas sino más bien beneficios extraordinarios. Para verificarse tal conclusión puede observarse que, en los primeros cuatro años de concesión, la recaudación de las empresas, por concepto de peaje, tuvo una tasa de incremento media de $447 \%$. Si bien, el mayor incremento se produjo el primer año, donde la tasa total de incremento fue del $172 \%$, también se verifican importantes incrementos luego de la primera renegociación. En tal sentido, 
si se tomara como base el segundo año (noviembre 1991-octubre 1992, en el que se producen los acuerdos de renegociación) se observa una tasa de incremento del $50 \%$ con relación a noviembre 1993- octubre de 1994 (último período antes de que se produzca una nueva renegociación).

Los mayores beneficios de los concesionarios no se deben exclusivamente al aumento en la tarifa sino que además hubo un aumento del tránsito vehicular diario y fueron compensados a través de subsidios. Dichos subsidios, otorgados a partir de los acuerdos de 1992, ascendían a \$67.766.220 anuales. A estas consideraciones, debe agregarse el casi nulo incremento en los precios, lo que permitiría concluir que la primera de las renegociaciones terminó generando beneficios extraordinarios para las empresas.

Se desprende de la descripción de la primera renegociación que tampoco con ella se logró establecer un marco regulatorio claro y transparente, que fijara reglas de juego para encuadrar las relaciones entre los concesionarios, el Estado y los usuarios de las redes viales. Transcurridos cuatro año de la concesión de las rutas, y superado un proceso de renegociaciones, se había perdido una nueva oportunidad de resolver la opacidad de los contratos y las obligaciones de los distintos actores por la concesión de las rutas.

En abril de 1995 se inició una segunda ronda de renegociaciones. La nueva renegociación se sustentaba en la necesidad de revisar los contratos originales por el extraordinario incremento del transito vehicular y la mayor utilización de los corredores viales. Nuevamente, se argumentaba la incapacidad del Estado para revertir las condiciones de una red vial obsoleta y, frente a ello, los concesionarios eran presentados como los actores capaces de llevar adelante las obras necesarias para ampliar y mejorar las carreteras. El restante argumento que motivaba la nueva renegociación era la necesidad de evitar mayores erogaciones del Estado en los contratos en los que se otorgaban subsidios y/o compensaciones indemnizatorias. En consecuencia, tres años después de haber reprogramado el plazo para la finalización de la concesión y el plan de inversiones de los concesionarios, se produjo una nueva renegociación. Así, las revisiones en los contratos se sucedían, la normativa del sector se multiplicaba pero la red vial seguía sin mejorar: el estado de la calzada se mantenía en niveles similares a los que tenía al momento de realizarse la concesión y tampoco se habían incrementado los ingresos del área de forma de permitir un incremento en la extensión de la red o una mejora en los caminos no concesionados. A contramano de lo que señalaba al momento de la concesión, el traspaso a manos privadas de la gestión de los caminos no generó nuevos recursos al estado. Por el contrario, la pronta renegociación hizo que el Estado terminara destinando recursos de sus arcas para subsidiar a los concesionarios. En definitiva, el inicio de las nuevas renegociaciones no hacía más que mostrar la falta de previsión estatal y un modus operandi que garantizaba beneficios extraordinarios a las empresas concesionarias. 
Este proceso de renegociaciones se convertiría en el más largo y prolongaría una situación de incertidumbre. Sólo el corredor vial 18 -en el cual se vio el mayor incremento de tránsitollegaría a un acuerdo de renegociación ese mismo año. Dicha renegociación resultó en una ampliación del plazo de concesión por 15 años más, la reprogramación de los planes de inversión y los índices esperados de estado de rutas. Así como también se incorporó una nueva obra ${ }^{13}$ y se fijó una nueva tarifa (dolarizada), por lo que se garantizaba también que cualquier variación impositiva podría ser trasladada en forma inmediata a los usuarios. Asimismo, se ratificó la inexistencia - para este corredor - de avales o subsidios y se incluyó la responsabilidad de reinvertir en nuevas obras.

Se produjeron cambios en los gabinetes ministeriales y en los gobiernos, pero la renegociación con los restantes concesionarios siguió sin resolverse. En noviembre de 2000 se firmaron las Actas de Acuerdo que establecían las tarifas, las compensaciones indemnizatorias y definían, en cada uno de los casos, la correspondiente cuota mensual a percibir por ese concepto. Entre los principales puntos del acuerdo se encontraban: la eliminación de la obligación del concesionario de realizar obras del contrato original; el reconocimiento estatal de una deuda y el compromiso de pago; un procedimiento para la revisión de las penalidades (pues se consideraba que algunos incumplimientos de los concesionarios podían ser producto de incumplimientos estatales). No se acordó ninguna prórroga a la concesión, aunque se establecía que si el Estado no cumplía con la totalidad de las deudas reconocida, el concesionario podría continuar explotando el corredor hasta que fuera saldada ${ }^{14}$. Como contraparte, se establecía una reducción en las tarifas, la cual se daba en forma paralela a la implementación de un Régimen de Subsidio Temporal para el Transporte y se eliminaba el ajuste sobre la base de la tasa LIBOR (aprobado en la primera renegociación realizada).

En definitiva, a partir de la nueva renegociación, el Estado se comprometía al pago de algo más de U\$S 900 millones. en calidad de distintos tipos de subsidios, pagos que deberían ser abonados, entre septiembre de 2001 y octubre de 2003 (el final del período de concesión). El tratamiento diferenciado de cada uno de los corredores, las negociaciones individualizadas, la alta heterogeneidad y poca claridad de la normativa, la diversidad de subsidios y condiciones acordadas atentaron contra el alcance de los objetivos establecidos al comienzo del proceso. Nuevamente, las intenciones originales que justificaban la apertura de un proceso de revisión de contratos eran modificadas a fin de favorecer a los concesionarios. Sin embargo, el acuerdo alcanzado en 2001 debió ser revisado en virtud de las nuevas condiciones impuestas por la

13 La Autopista Brazo Largo-Ceibas que por su costo estimado (alrededor de U\$S 63 millones más IVA) podría considerarse como una licitación de obra sin licitación previa.

14 Acordándose que en el período de prorroga la concesión, el concesionario no tenía obligación de mantener las exigencias contractuales. 
Ley de Emergencia promulgada luego de los sucesos que derivaron en la salida anticipada de Fernando De la Rúa (1999-2001).

Tras la sucesión de cinco presidentes constitucionales, en poco más de una semana, y producida la declaración unilateral de la cesación de pagos de los intereses de la deuda externa, fue designado como presidente provisional Eduardo Duhalde (2002-2003). El nuevo gobierno con el acuerdo de la mayoría legislativa promulgó la Ley de "Emergencia Pública y Reforma del Régimen Cambiario", a través de la cual se introdujeron transformaciones esenciales a las reglas de juego imperantes. Además, se derogó la Convertibilidad, se depreció el peso y quedaron sin efecto las cláusulas de indexación o ajuste en dólares.

Dicha ley daba inicio a un nuevo período de renegociación ${ }^{15}$. Entretanto, se impedía a las empresas contratistas o prestadoras de servicios públicos la posibilidad de suspender 0 alterar el cumplimiento de sus obligaciones. En el crítico contexto que se estaba viviendo, las presiones de las empresas prestadoras de servicios públicos ${ }^{16}$, los gobiernos extranjeros -cuyos empresarios tenían inversiones en las empresas argentinas de servicio público-y los organismos internacionales no tardarían en llegar, lo mismo que los rumores de incrementos de las tarifas.

Una nueva renegociación, la tercera, se iniciaba. Como en las otras oportunidades, se evaluó a cada uno de los corredores viales por separado y, nuevamente, se observó una fuerte reticencia de los concesionarios a firmar los acuerdos. Las propuestas de las empresas concesionarias de corredores viales, cuyos plazos de concesión vencían en octubre de 2003, planteaban las siguientes modificaciones: extensión de los contratos de concesión; la reprogramación de planes de inversión; el incremento de los fondos provenientes del Fondo Fiduciario y modificaciones en la fórmula de ajuste.

Es posible observar que el mecanismo de indexación acordado en la primera renegociación (tasa LIBOR reducida en un 20\%) generó un incremento en las tarifas que se encontraba muy por encima de la inflación media del período, ya que alcanzó un promedio de 4,4\% mientras que la evolución del IPC (Índice de Precios al Consumidor) para el mismo período no superó el $0,12 \%$. En tanto, la variación de la recaudación de las empresas por concepto de peaje, tuvo un incremento constante que promedió un $56 \%$, muy por debajo de lo encontrado producto de la primera renegociación, pero muy elevados si se considera la etapa recesiva por la que estaba atravesando el país, fundamentalmente desde mediados de 1997/1998.

15 Más amplio porque era extensivo a todos los sectores.

16 Las amenazas de declararse en default, abandonar la prestación de los servicios, retirarse del país, despedir masivamente personal y presentarse en el Centro Internacional de Arreglo de Diferencias Relativas a Inversiones (CIADI) fueron moneda corriente. 
En el período analizado, han cambiado los gobiernos: una presidencia justicialista, a la cual sucedió una radical (más específicamente de la Alianza), para regresar a otra presidencia justicialista ${ }^{17}$, con lineamientos políticos que aparecen como opuestos a los del gobierno menemista. En términos políticos, hubo alternancia en el poder. En términos económicos, las renegociaciones viales han transcurrido en contextos signados por hiperinflación, estabilidad, recesión y declaración del default. No obstante, a pesar de las discontinuidades en los escenarios, se observan continuidades en términos de las características que adopta el vínculo del Estado con las empresas concesionarias. Las principales continuidades observadas en los procesos de renegociación resultan:

- La ausencia de un marco regulador. El entramado jurídico que reguló las concesiones viales realizadas en la década del ' 90 se conforma con una ley de fines de la década del ' 60 (Ley de Peaje), con modificaciones introducidas en 1989, a través de la Ley de Reforma del Estado, y las pautas fijadas en los pliegos licitatorios. Numerosos decretos y resoluciones se sucedieron completando las anteriores y favoreciendo la dispersión normativa.

- La incapacidad (o falta de voluntad) para llevar adelante acuerdos que establezcan claridad y transparencia al vínculo entre los concesionarios viales y el Estado. Todo el período estuvo marcado por el dictado de numerosas normativas y reglamentaciones establecidas con criterios dispares y hasta contradictorios entre sí, los cuales no tuvieron la capacidad de articular consensos que le permitan generar una situación de estabilidad y certidumbre.

- La acentuación de los problemas vinculados con la falta de diagramación y el estudio de las condiciones iniciales y riesgos existentes, por la falta de información confiable sobre los corredores viales (v.g. estado de las rutas, inversiones realizadas, rentabilidad de las empresas). La ausencia de un estudio sistemático sobre las probabilidades de cumplir con las obras presentadas por los consorcios que se presentan en las licitaciones trajo consecuencias irreparables que conjugadas con las falencias en los controles posteriores actuó incrementando la asimetría entre el concesionario y el concedente, en desmedro de la posición de los usuarios y la ciudadanía, en general, y aumentando la vulnerabilidad estatal.

- Las decisiones tomadas signaron una etapa de alta incertidumbre, ya que las medidas o acuerdos alcanzados podían ser rápidamente modificados. La incertidumbre no afectó de la misma manera y en el mismo sentido a los actores involucrados. Frente a los cambios en las decisiones siempre se reconoció a los concesionarios el pago de compensaciones.

17 En realidad, a fin de ser específicos tendríamos que referirnos a varias presidencias justicialistas sucediendo al gobierno de De la Rúa, pues fue sucedido por cinco presidentes hasta la elección que designa a Kirchner como presidente, en 2003. 
- Cada uno de los procesos de renegociación de contratos se fundamentaba inicialmente en la necesidad de revertir una situación que se presentaba como desfavorable para el usuario y/o el Estado (v.g. reducir -o sostener- la tarifa, eliminar las compensaciones a través de indexaciones, construir nuevos tramos de ruta o mejorarlos). Sin embargo, en cada renegociación, a cambio de esos objetivos se hicieron amplias concesiones a los empresarios.

- El valor de la tarifa, ha sido la cuestión centralmente considerada al momento de renegociar. Podría decirse, incluso, que fue el criterio exclusivo definido por el Estado. A fin de mantener estable la misma (o con la menor variación posible) se compensó en forma sistemática a los concesionarios.

- El lugar secundario que ocupó la necesidad de recaudar recursos para financiar obras de mantenimiento en los caminos no concesionados, un argumento central al momento realizar las licitaciones.

- Las empresas tendieron a plantear la extensión del plazo de concesión. Dicha tendencia tiende a incrementar los flujos de rentabilidad futura y crear barreras adicionales de ingreso al mercado (Azpiazu, 2002).

- La tendencia a priorizar los intereses de los empresarios. Argumentando la necesidad de sostener sus inversiones en el sector, y a fin de garantizar la seguridad jurídica, las decisiones estatales favorecieron la alta rentabilidad empresaria.

El rol marginal que cumplió en las renegociaciones el organismo regulador. En tales renegociaciones el Estado ha sido representado por instituciones, fundamentalmente, políticas (Ministerio de Economía y Secretaría de Obras Públicas y Concesiones $^{18}$. La alta exposición a la situación política (por encontrarse la decisión última en un funcionario político del Poder Ejecutivo) puede traer ciertos inconvenientes asociados con la potencial captura.

- La poca presencia del Congreso de la Nación y de los gobiernos provinciales. El Congreso no han participado activamente delineando ni aprobando las actas de acuerdo, sólo se verifican algunos informes críticos de la Comisión Especial. Entretanto, los gobiernos provinciales sólo han tenido períodos muy breves de activación en torno a esta cuestión.

- Los mecanismos de accountability horizontal tampoco resultaron efectivos. Se han presentado algunos informes muy críticos, pero en su mayoría su impacto fue bajo o presentados a destiempo, por lo que no sirvieron para revertir las acciones gubernamentales.

18 Se utiliza esta denominación de forma genérica, aún cuando en el período estudiado se produjeron algunas variaciones en la forma de denominar estas unidades. 
- El período estuvo enmarcado por las críticas de los productores, transportistas y otras asociaciones. El conflicto tendió a expresarse en algunos sectores en particular pero no se hizo masivo.

En síntesis, describimos un período signado por la alta incertidumbre y la ausencia de claridad en las reglas de juego para algunos jugadores. Las constantes modificaciones en las regulaciones terminaron favoreciendo siempre al mismo sector: los concesionarios, quienes tenían la "certidumbre" de ser compensados frente a cualquier modificación de las condiciones iniciales. Así, la inseguridad jurídica fue, en realidad, funcional a los intereses empresarios.

\subsection{El segundo modelo de regulación}

Apenas asumida la gestión Kirchner, se definió que los contratos de explotación de rutas por peaje, tal como se fijó en la primera renegociación, terminaran ${ }^{19}$ y se llamara a una nueva licitación. En la convocatoria se indicaba que ningún postulante podía ser adjudicatario de más de un corredor, salvo cuando se diera el caso de una oferta única.

TABLA 2: Concesiones viales realizadas en octubre de 2003

\begin{tabular}{|c|c|c|c|c|c|c|c|c|}
\hline \multirow{2}{*}{ CV } & \multirow{2}{*}{ Rutas } & \multirow{2}{*}{ Longitud } & \multirow{2}{*}{ Modalidad } & \multirow{2}{*}{ Canon } & \multirow{2}{*}{ Subsidio } & \multirow{2}{*}{ Concesionaria } & \multicolumn{2}{|c|}{ Composicion Accionaria } \\
\hline & & & & & & & Empresa & $\%$ \\
\hline \multirow[t]{2}{*}{1} & \multirow{2}{*}{$\begin{array}{l}3.205 \\
226.252\end{array}$} & \multirow[t]{2}{*}{1280.17} & \multirow[t]{2}{*}{ Onerosa } & \multirow[t]{2}{*}{$4,20 \%$} & \multirow[t]{2}{*}{-} & \multirow[t]{2}{*}{ Rutas del Sur S.A. } & EQUIMAC SA & 50 \\
\hline & & & & & & & COARCO SA & 50 \\
\hline \multirow[t]{2}{*}{2} & \multirow[t]{2}{*}{5.7} & \multirow[t]{2}{*}{$1.265,68$} & \multirow[t]{2}{*}{ Onerosa } & \multirow[t]{2}{*}{$15,01 \%$} & \multirow[t]{2}{*}{-} & \multirow[t]{2}{*}{ Autovia del Oeste SA } & HOMAC SA & 99,9 \\
\hline & & & & & & & Fabio Clebañer & \\
\hline \multirow[t]{2}{*}{3} & \multirow{2}{*}{$\begin{array}{l}9 \text { AU Ros } \\
\text { A-012.11A } \\
009.19188\end{array}$} & \multirow[t]{2}{*}{1.500 .133} & \multirow[t]{2}{*}{ Onerosa } & \multirow[t]{2}{*}{$32,11 \%$} & \multirow[t]{2}{*}{ - } & \multirow[t]{2}{*}{ VIAL 3 SA } & DECAVIAL SA & 50 \\
\hline & & & & & & & VIALCO SA & 50 \\
\hline \multirow{3}{*}{4} & \multirow{3}{*}{$\begin{array}{l}8,33,36 \\
38,193 \\
A-005\end{array}$} & \multirow{3}{*}{$1.219,39$} & \multirow{3}{*}{ Onerosa } & \multirow{3}{*}{$7,77 \%$} & & Caminos de America & Corpor. Americana & 86,9 \\
\hline & & & & & - & SA & HELPORT SA & 13 \\
\hline & & & & & & & PODESTA Construcc. & 0,1 \\
\hline 5 & 9,34 & $1.514,13$ & Onerosa & $21,00 \%$ & - & Vial Cinco SA & COVINCO CONCES & \\
\hline & & & & & & & VIAL SA & 42,25 \\
\hline & & & & & & & $\begin{array}{l}\text { COPRESA SA } \\
\text { ESTRUCTURA }\end{array}$ & 11,95 \\
\hline & & & & & & & SACICIF & 11,45 \\
\hline & & & & & & & GLIKSTEIN Y CIA & \\
\hline & & & & & & & SACIAM & 11,45 \\
\hline & & & & & & & $\begin{array}{l}\text { ILF SA } \\
\text { NOROESTE }\end{array}$ & 11,45 \\
\hline & & & & & & & CONSTRUC SA & 11,45 \\
\hline 6 & 11,12 & 1.150 .24 & Subvencionada & $33,21 \%$ & - & Empresa concesionaria & SUPERCEMENTO SA & 60 \\
\hline & 16 & & & & & Vial SA & $\begin{array}{l}\text { DRAGADOS y OBRAS } \\
\text { PORTUARIAS SA }\end{array}$ & 40 \\
\hline
\end{tabular}

Fuente: Elaboración propia en base a información del decreto de concesión y demás información brindada por el OCCOVI.

19 La excepción son los CV 18-que renegoció 15 años de prórroga- y el CV 29 que fue licitado posteriormente. 
La nueva concesión se caracterizó porque:

- Tal como podemos observar en el cuadro 2, los 17 corredores viales cuyas concesiones finalizaron se reagruparon en 6 , con el objetivo de establecer subsidios cruzados entre rutas y corredores.

- El plazo de concesión se estableció en 5 años.

- Los concesionarios podrían ser empresas conjuntas o individuales, pero las acciones no podrían transferirlas a terceros, ni entre los mismos, hasta el cuarto año de concesión.

- Los ingresos podían provenir de las tarifas cobradas, los ingresos por la explotación de las áreas de servicio (o en el CV 6 por subvenciones). Se estableció que todos los ingresos debían depositarse dentro de las 48 horas hábiles en la Caja Única ${ }^{20}$, desde donde se trasferirían los fondos -luego de que se dedujeran los intereses resarcitorios ${ }^{21}$ no pagados por la concesionaria, los montos de las multas aplicadas, el monto de canon fijado, el importe de las garantías- a la cuenta del concesionario. Asimismo, se utilizaría para financiar obras de inversión licitadas por separado y podría percibir aportes de organismos multilaterales de crédito.

- En cuanto a las tarifas, podrían indexarse sobre la base de aumentos en los costos de los insumos.

- En el caso de los corredores onerosos, el Estado estableció un canon mínimo como base y adjudicó en función del oferente que cotizó el canon más alto. En tanto, la selección del concesionario para el corredor 6 se realizó al que propusiera el mínimo subsidio.

- No se establecían garantías de riesgo, pero el Estado se reservaba el derecho de incorporar nuevos tramos al corredor. Así, podría realizar obras de cualquier naturaleza dentro de la zona de camino del corredor concesionado. Para la realización de estas obras de mejora, el Estado debería licitar el tramo. La concesionaria podría participar de dicha licitación. En definitiva, se establecieron dos tipos de licitaciones: 1) las de mantenimiento, que fueron las realizadas en octubre de 2003 y 2) las de pavimentación y obra, las cuales se estimaban en un promedio de 30 por año.

- Los nuevos contratos fijaron que la pavimentación y las obras de mejoras y ampliación de las redes serían responsabilidad exclusiva del Estado, que debería encargarse de licitar, financiar y supervisar las obras. Por su parte, los empresarios privados deberían responder por el mantenimiento, conservación y prestación de los servicios al usuario de ruta y podían obtener ingresos también por medio de la explotación de áreas de servicios (v.g. estaciones de servicio, moteles, centros comerciales, confiterías, restaurantes y esparcimiento).

20 El sistema de Caja Única dio lugar a la integración de un fondo fiduciario, a quien las concesionarias ceden sus derechos de cobro de peaje y demás ingresos de la concesión.

21 Se refiere a los intereses por mora. 
- Se definía a la concesionaria como responsable de la seguridad y transitabilidad, así como del mantenimiento del inventario actualizado de los bienes muebles e inmuebles que conformaban la concesión.

\subsection{Dos modelos, algunas continuidades}

En los puntos anteriores se han caracterizado dos modelos de concesión/regulación de redes viales diferentes. El primer modelo, cuyas características iniciales se definieron en 1989 y que, tal como pudo observarse, sufrió innumerables variaciones y el segundo, instaurado en 2003 (con las excepciones antes indicadas), en un contexto macroeconómico diferente y con una experiencia de más de una decena de años.

La inexistencia de renegociaciones y la ausencia de subvenciones (sólo otorgadas al corredor vial 6) parecen indicar que el modelo de concesiones viales otorgadas en 2003 fue más efectivo en su defensa del interés público. No obstante, ambos se caracterizan por su opacidad. En el segundo modelo, la regulación que se ejerce parece quedar exclusivamente asociado al recorte de funciones a los concesionarios. Así, se evitan algunos problemas vinculados con el modelo anterior. Sin embargo, persistieron problemas, fundamentalmente, los asociados con la discrecionalidad en el manejo de los fondos públicos que, nuevamente, beneficiaron a los empresarios de la construcción aunque en este segundo modelo no se dieron a partir de la operación de los caminos sino por la licitación de las obras de mejora de los caminos.

Respecto al rol del organismo regulador, es evidente que el modelo instaurado en 2003 dio mayor participación al mismo. Sin embargo, esto no ocurrió en función de reforzar sus aspectos regulatorios, sino por el incremento - a partir de un liderazgo en particular ${ }^{22}$-, de las características operativas de prestación de un servicio de mantenimiento y realización de obras.

Es interesante destacar en la comparación de los dos modelos de concesión/ regulación que, aún cuando el segundo modelo surge en una etapa fuertemente crítica del modelo de concesión y regulación implementado en la década del ' 90 no impuso una revisión de los impactos del proceso precedente. Al momento de definir las características de la nueva licitación de rutas nacionales se planteó la necesidad de realizar una revisión de los resultados previos e, incluso, algunos funcionarios señalaban que las empresas con un mal desempeño no podrían participar de las nuevas licitaciones. Esto no ocurrió, ya que nuevamente la "urgencia" enmarcó el proceso de licitaciones. Así, el nuevo modelo se impuso como una especie de "borrón y cuenta nueva"23. Aparentemente, un nuevo juego comenzaba. Sin embargo, aún cuando algunas reglas pudieron

22 Desde 2003 y hasta 2007 se desempeñó como Director Ejecutivo del organismo un funcionario altamente ligado con el Presidente.

23 Agradezco a Martín Schorr la referencia a esta cuestión. 
cambiar, las cartas y los jugadores seguían siendo los mismos. Incluso, si bien muchas empresas que conformaban los consorcios en el período 1990-2003 no fueron parte de las nuevas concesiones se mantenían en el juego, ya que participaron de las licitaciones de obras.

Aún cuando se observaron importantes diferencias en el diseño de ambos modelos, existe una importante continuidad en términos de las capacidades estatales. A pesar de la estabilidad de los contratos originales, de la mayor visibilidad de la agencia reguladora, de la mayor recaudación de recursos estatales y el fin de las compensaciones indemnizatorias, es evidente que la acción del Estado siguió favoreciendo a los mismos actores. El cambio de modelo, no implicó una revisión profunda de los resultados e impactos de la etapa anterior. Ni siquiera la renegociación de los contratos, prevista por la Ley de Emergencia (2002) generó las condiciones para el análisis del cumplimiento de los contratos. Así, el nuevo modelo se estableció sobre los restos del anterior. Nuevamente primaba el desconocimiento sobre el estado del patrimonio que se estaba concesionando y el juego se abrió a las empresas, sin que se considerase su desempeño previo. En el nuevo modelo de concesión de las redes viales, la posibilidad de actuar como contratistas de obra les generó a los empresarios de la construcción nuevas posibilidades de reproducir sus ganancias. Por ello, aún cuando algunas empresas no participaron de las licitaciones de los corredores viales (v.g. Techint, Benito Roggio, Sideco Americana) se beneficiaron a partir del retorno a su negocio original, la construcción, reparación y mejora de los caminos. En síntesis, al igual que en la década del ' 90 , se establece un modelo de regulación funcional a los intereses empresarios. No obstante, las condiciones de contexto han cambiado y con ello también lo ha hecho la forma de garantizar los beneficios a uno de los sectores más tradicionales del empresariado nacional.

En cuanto a la dinámica de funcionamiento del sector, se observa una importante continuidad en términos de su opacidad. En el primer modelo, la falta de transparencia se evidencia en los constantes cambios de reglas de juego a través de las renegociaciones. En el segundo, se observa una mayor persistencia de las reglas de juego, pero la opacidad se manifiesta en el manejo de los fondos. En el segundo modelo de concesiones, el organismo de control tiene un rol clave, pero no como regulador, sino como administrador de recursos y en su capacidad de realización de obras en los tramos concesionados. La agencia de control, a través de un liderazgo marcado de su director ejecutivo, ha pasado a ocupar un rol central en el esquema de la obra pública en Argentina. Sin embargo, ello no implicó una mejora significativa en el índice de estado de los caminos.

Por otra parte, resulta evidente la fragmentación de funciones asociadas con la regulación del sector. Aún cuando el OCCOVI ha cobrado impulso a partir de 2003, la multiplicación de instituciones con funciones vinculadas a la planificación, organización y control de los caminos, en general, y de las rutas concesionadas, en particular, es un elemento para explicar la baja capacidad del Estado para regular. La superposición de funciones y los vacíos, en términos de 
lo que se considera un efectivo modelo de regulación sectorial, son un exponente de la baja capacidad regulatoria específica, además de ser una muestra de que el Estado que se configura luego del fin de la convertibilidad tampoco parece dar un espacio de relevancia a la cuestión de la regulación. En algunos sectores se renegociaron los contratos (v.g. distribución eléctrica, algunas autopistas y transportadoras de energía eléctrica), en otros se finalizó en forma anticipada (v.g. correo); en otros se volvieron a estatizar las empresas privatizadas en la década anterior (v.g. agua y saneamiento) 0 , a partir de los enfrentamientos, se crearon empresas estatales (v.g. Energía Argentina SA, ENARSA; Líneas Aéreas Federales SA, LAFSA), pero en ninguno de los casos se produjo una profunda revisión de la situación preexistente en el sector. Los enfrentamientos con los empresarios de las privatizadas fueron evidentes en los primeros tiempos del gobierno de Kirchner, pero aún cuando se optó por la finalización anticipada de los contratos o la estatización, la opción pareció más un producto de la decisión empresaria de retirarse que el resultado de una firme intención del Estado de revisar las condiciones de contratación y fortalecimiento de su rol como regulador.

En asociación con lo planteado en el párrafo anterior, es de destacar como una importante continuidad de los dos modelos: el rol central desempeñado por el Poder Ejecutivo Nacional, en términos de la concentración del poder de decisión. Si bien los nombres de los funcionarios han variado, las dinámicas de interacción subsistieron. El Ministerio que tiene a su cargo las funciones asociadas con la planificación de obras públicas, a través de la Secretaría que cumple especificamente con dichas funciones, establece los lineamientos centrales y actúa a lo largo de todo el proceso. El resto de las agencias e instituciones establecen sus estrategias y acciones a partir de lo dispuesto por éstas y el Poder Legislativo y los gobiernos provinciales y municipales -por cuyos territorios atraviesan los caminos concesionados- son sistemáticamente excluidos de los ámbitos de tomas de decisión. En tanto, las resoluciones o intervenciones de organismos de control como la Auditoría General de la Nación (AGN) - control externo -, el Defensor del Pueblo, la Procuraduría y la Sindicatura -control interno- han sido desestimadas al momento de la negociación con los empresarios del sector o la reorganización institucional. Inclusive, el fortalecimiento del OCCOVI es un indicador de la discrecionalidad del Ejecutivo Nacional. La importancia del organismo resulta, entonces, de los vínculos informales existentes entre el Director Ejecutivo del organismo, el Ministro de Infraestructura y el Presidente.

La diferenciación entre los dos modelos de concesiones viales implantados en el período de estudio se sustentan en argumentos técnicos. Sin embargo, la regulación es también, y centralmente, una cuestión política. En tal sentido, más allá de las diferencias técnicas al subsistir la misma lógica de articulación social y la situación de debilidad estatal se reprodujeron la captura empresaria y la cooptación política sobre las actividades de regulación sectorial. En esa dinámica de comportamiento, es evidente que los grandes perdedores resultaron los usuarios de los caminos. No obstante, existen significativas diferencias respecto de, por ejemplo, 
los servicios domiciliarios, pues los usuarios de las rutas concesionadas ejercieron cierta capacidad de presión que permitió que las tarifas no aumentaran en la medida en que los acuerdos con los concesionarios lo establecían. Para ello, el Estado actúo otorgando subsidios y demás compensaciones (cuestión que fue más evidente en la caracterización del primer modelo). Por otro lado, algunos usuarios con mayor capacidad de presión -v.g. empresarios del transporte de pasajeros y carga- obtuvieron subsidios directos e indirectos a sus actividades. En tanto, podría concluirse que los principales perjudicados resultaron los usuarios de caminos no concesionados ya que los mismos no tuvieron mejoras debido a que los recursos del Estado siguieron orientándose a los caminos concesionados, mientras los caminos alternativos siguieron presentando importantes déficit y ha sido irrelevante el impacto de los nuevos.

TABLA 3: Los dos modelos de concesión/regulación en perspectiva comparada

\begin{tabular}{|c|c|c|}
\hline Características & Modelo de Concesiones Viales 1989 & Modelo de Concesiones Viales 2003 \\
\hline Propósito de la concesión & $\begin{array}{l}\text { Explotación, administración, conservación y } \\
\text { mantenimiento obras realizadas }\end{array}$ & $\begin{array}{l}\text { Explotación y administración. Solo corresponde a } \\
\text { concesionario la realización de algunas obras } \\
\text { menores de mejoras. }\end{array}$ \\
\hline Duración de la concesión & $\begin{array}{l}\text { Inicialmente } 12 \text { años } \\
\text { Prorrogado a } 13 \text { años para } 16 \mathrm{CV} \\
\text { extendido a } 28 \text { años para } 1 \mathrm{CV}\end{array}$ & 5 años \\
\hline Kilómetros concesionados & $\begin{array}{l}9.383 \mathrm{Km} \\
(+\mathrm{CV} 29)\end{array}$ & $\begin{array}{l}7.954 \mathrm{~km} . \\
\text { (+CV } 18 \text { y } 29 \text { concesionados en la etapa anterior) }\end{array}$ \\
\hline Número de consorcios & 12 & $\begin{array}{l}6 \\
(+2 \text { de la concesión anterior })\end{array}$ \\
\hline Tipo de concesión & $\begin{array}{l}\text { Subsidiada. Si bien, originalmente solo un CV tenía } \\
\text { este reasgo, todos terminaron siendo subvencionados } \\
\text { por el Estado (a excepción de un CV) }\end{array}$ & $\begin{array}{l}\text { Onerosa (a excepción de un CV) } \\
\text { SIstema administrado a través de una Caja Unica }\end{array}$ \\
\hline $\begin{array}{l}\text { Grado de decisión del } \\
\text { concesionario }\end{array}$ & $\begin{array}{l}\text { ALTO } \\
\text { En función de los planes de obra y la aprobación de } \\
\text { propuestas tiene amplio margen para la definición de } \\
\text { las obras y su característica. }\end{array}$ & MUY BAJO \\
\hline Fondos para las obras & $\begin{array}{l}\text { Privados. No obstante a partir de los subsidios y otras } \\
\text { modificaciones contractuales, podría decirse que eran } \\
\text { fondos públicos administrados por privados. }\end{array}$ & $\begin{array}{l}\text { Públicos. Se realizan nuevas licitaciones para la } \\
\text { realización de grandes obras. Si bien, no se } \\
\text { obtuvieron datos oficiales, fuentes del organis mo } \\
\text { señalaron que entre } 2003 \text { y } 2005 \text { se realizaron } \\
\text { alrededor de } 60 \text { obras, con estas características. } \\
\text { Privados; para la conservación, explotación, } \\
\text { mantenimiento y porestación de servicios usuarios. }\end{array}$ \\
\hline Renegociaciones & $\mathrm{SI}$ & NO \\
\hline Organismo de control & $\begin{array}{l}\text { DNV, OCCOV, OCCOVI (según el periodo dentro de la } \\
\text { concesión) }\end{array}$ & $\begin{array}{l}\text { OCCOVI } \\
\text { En este modelo es además responsable de } \\
\text { planificar las obras y realizar el llamado a licitación } \\
\text { para la realización de las mismas. }\end{array}$ \\
\hline $\begin{array}{l}\text { Participación del organismo } \\
\text { regulador en la concesión }\end{array}$ & $\begin{array}{l}\text { NO } \\
\text { La función de control y regulación se estableció en } \\
\text { forma posterior a la licitación y concesión. }\end{array}$ & $\begin{array}{l}\text { SI } \\
\text { El Organismo precedió al proceso de las nuevas } \\
\text { licitaciones. }\end{array}$ \\
\hline Autonomía & $\begin{array}{l}\text { Recién en el período final de la concesión (últimos } 2 \\
\text { años) }\end{array}$ & $\mathrm{SI}$ \\
\hline Ejecución de obras & DNV (fuera de la red concesionada) & $\begin{array}{l}\text { DNV (Fuera de la red concesionada) } \\
\text { OCCOVI (en la red concesionada) }\end{array}$ \\
\hline
\end{tabular}




\section{La debilidad estatal: transformaciones en las organizaciones y subsistencia de la problemática vial}

El estudio del caso de las concesiones viales y la relación entre el Estado y los empresarios del sector sirve para sostener la proposición que señala que las oposiciones de los actores sociales, en y a través del Estado, contribuyen al debilitamiento de un marco social e institucional ya débil pues los distintos actores de la sociedad civil pugnan por insertar directamente sus intereses de grupo en el Estado. Así, la autonomía relativa del Estado se ve reducida y se genera un circulo que redunda en que algunos grupos tengan más poder y capacidad de acceso a la toma de decisiones mientras que otros pueden, en términos formales, participar de la red decisional pero, en términos reales, quedan cada vez más aislados de esos espacios. En definitiva, el Estado pierde potenciales aliados y, con ellos, su capacidad de imponerse en las relaciones sociales. Este aspecto redunda en un fortalecimiento de los actores que aparecian desde un principio recortando la autonomía relativa del Estado (los sectores más poderosos, según nuestra hipótesis de trabajo, los grupos económicamente más consolidados del país).

Si se considera que la regulación es la otra cara de la privatización/ concesión y, por lo tanto, que cuando el Estado privatiza la operación o prestación de un bien o servicio público aceptando la existencia de un monopolio privado- debe controlar acorde a los valores públicos; podría suponerse que con la Reforma del Estado, iniciada en la década del ' 90 , ingresó en la agenda pública la cuestión de la regulación. Sin embargo, por ese entonces, la cuestión que acaparaba la agenda del gobierno era la reducción del déficit fiscal y la desinversión en el sector. Frente a ello, los restantes aspectos fueron desplazados a un lugar secundario. Respecto de la regulación se consideraba que la sociedad operaría como controlante de las actividades realizadas por las empresas. En los meses iniciales de la primera concesión, la movilización popular -asociada principalmente con el costo de las tarifas de peajes- motivó la "intervención" estatal, la cual no se orientó a la explicitación de un marco regulatorio sino a la creación de normas particulares que se superponían, y hasta contradecían, entre sí. Las renegociaciones de contratos marcaron el pulso de las relaciones entre los actores del sector. No obstante, tampoco indicaron la problematización de la cuestión de la regulación, sino resoluciones de compromiso a aspectos particulares.

Es posible afirmar que el proceso privatizador desplazó al Estado como propietario de numerosas empresas de servicios, pero no creó nuevas condiciones para asegurar el óptimo funcionamiento del sector. El segundo modelo de concesiones tampoco se preocupó por la regulación. No sería el fuerte déficit fiscal sino la inestabilidad política y la crítica situación socioeconómica la que imponía restricciones para el surgimiento de la cuestión en la agenda gubernamental.

En tales circunstancias, aún cuando podría suponerse que se impuso una perspectiva de la regulación reduccionista, no fue así ya que no se han cumplido siquiera con los objetivos 
mínimos que caracterizan esa perspectiva. En tal sentido, es evidente, por ejemplo, que no se redujeron los riesgos de la incertidumbre, ni se garantizaron reglas generales y homogéneas. Tampoco se implementó un modelo de light regulation (regulación liviana) ${ }^{24}$ porque en el caso estudiado no hubo ausencia de normas sino que estas se han multiplicado y han mostrado una injerencia permanente del Estado a lo largo del período estudiado. En términos de analizar lo que efectivamente se ha regulado, se observan dos problemas subyacentes:

- El primero, vinculado con la confiabilidad de la información utilizada para ejercer el control ya que la principal fuente de información es el concesionario, lo que refuerza la asimetría de información.

El segundo, la inestabilidad institucional. Los continuos cambios en los organismos reducen las responsabilidades de control y complejizan, por los problemas en el traspaso de los registros, un análisis de la evolución del comportamiento de los concesionarios y el sector. Dicho problema se fortalece por la fragmentación de funciones regulatorias entre distintos organismos.

La discontinuidad regulatoria, casi constante en el sector, se refleja claramente en el análisis de los organismos encargados de llevar adelante la regulación. En los contratos de concesión se establecía que se constituiría un órgano de control con funcionarios de la DNV y con una firma consultora privada. Dicho órgano de control entraría en vigencia a partir de la firma del mismo, aunque recién en 1990 se creó dentro de la DNV un equipo de fiscalización cuyas funciones se recortaban al control técnico y no a aspectos legales, sociales y económicos.

Recién después de realizada la primera renegociación se creó, en el ámbito de la DNV, el organismo responsable de la regulación de las concesiones de rutas nacionales: el Órgano de Control de Concesiones Viales (OCCV). Sin embargo, no sería hasta mayo de 1993 que dicho organismo entraría en funciones. No se asignaron al OCCV facultades decisorias para establecer políticas, ordenamientos y ajustes a nivel de tarifas o compensación indemnizatoria, responsabilidades que conservó la Secretaría de Obras y Servicios Públicos del Ministerio de Economía (Estudio especial AGN, 210-2004).

En 1993 fue creado el organismo responsable de la regulación de la red de Accesos a Buenos Aires (OCRABA), el cual fue fusionado hacia 2001 con el OCCV conformando una agencia descentralizada responsable del control de las concesiones viales: el OCCOVI. Este nuevo organismo sería responsable no sólo de ejercer la supervisión, inspección, auditoria y seguimiento del cumplimiento de los contratos de concesión de los corredores viales, sino también de la Red de Acceso a Buenos Aires, la Red de Acceso a Mendoza y el Puente Victoria-

24 Davis y Flanders (1995) definen este modelo de regulación, en contraposición con el de though regulation, señalando que disminuye las regulaciones y permiten una mayor explotación del poder del monopolio. 
Rosario. En tal sentido, se transfirieron competencias, objetivos, partidas presupuestarias y recursos humanos de los tres organismos antes mencionados.

La justificación formal de la necesidad de crear este nuevo organismo no radicó en una necesidad de fortalecimiento institucional sino en "producir un ahorro genuino al Presupuesto Nacional". Por ello, más allá de la denominación que adquiriera el organismo responsable de regular el sector, es evidente que el rol jugado a lo largo de la primera concesión de redes viales ha sido muy limitado. La Secretaría de Obras Públicas siempre ha desarrollado un papel principal al momento de discutir las reglas de juego y condiciones de servicio.

TABLA 4: Características de los organismos que cumplieron las funciones de control en distintos periodos históricos.

\begin{tabular}{|c|c|c|c|}
\hline Características & DNV & OCCV & OCCOVI \\
\hline Origen & $\begin{array}{c}\text { Ley } 11.658 \\
\text { (creación DNV) } \\
\text { Decr. 823/89* } \\
\text { (Reconversión vial) }\end{array}$ & $\begin{array}{c}\text { Res. DNV 81/92 } \\
\text { (crea la unidad) } \\
\text { Res. DNV 722/93 } \\
\text { (atribuciones y funciones) }\end{array}$ & $\begin{array}{c}\text { Decr. 87/01 } \\
\text { (crea organismo) } \\
\text { Decr. 1915/04 } \\
\text { (Asigna atribuciones para } \\
\text { contratación y ejecución de obras) }\end{array}$ \\
\hline Alcance del Control & $\begin{array}{l}\text { Control técnico de las } \\
\text { concesiones de rutas } \\
\text { nacionales }\end{array}$ & $\begin{array}{l}\text { Control técnico, legal y financiero } \\
\text { de las concesiones de rutas } \\
\text { nacionales }\end{array}$ & $\begin{array}{l}\text { Control técnico, legal y financiero de } \\
\text { las concesiones de rutas nacionales, } \\
\text { redes de acceso a Bs.As. y Mendoza } \\
\text { y PuenteRosario-Victoria }\end{array}$ \\
\hline Concesiones reguladas & 18 corredores viales & 18 corredores viales & $\begin{array}{l}18 \text { corredonres viales ** } \\
4 \text { autopistas de acceso a Bs.As. } \\
1 \text { autopista de acceso a Mendoza } \\
\text { Puente Rosario-Victoria }\end{array}$ \\
\hline Tipo de administración & Autárquico & Unidad organizativa & Descentralizado \\
\hline Dependencia Jerárquica & $\begin{array}{l}\text { Secretaria de Obras } \\
\text { Publicas }\end{array}$ & DNV & $\begin{array}{l}\text { Descentralizado en la órbita de la } \\
\text { Secretaría de Obras Públicas }\end{array}$ \\
\hline Autoridades & $\begin{array}{l}\text { Director Nacional de } \\
\text { Vialidad (nombrado por el } \\
\text { PEN) y un Consejo } \\
\text { Directivo }\end{array}$ & & $\begin{array}{l}\text { Dirección Ejecutiva (Director } \\
\text { Ejecutivo y Subdirector Ejecutivo) }\end{array}$ \\
\hline $\begin{array}{l}\text { Nombramiento de las } \\
\text { Autoridades }\end{array}$ & $\begin{array}{l}\text { El Director Nacional es } \\
\text { nombrado por el PEN }\end{array}$ & $\begin{array}{l}\text { La DNV era responsable de } \\
\text { definir las autoridades y todo el } \\
\text { equipo de trabajo del organismo }\end{array}$ & $\begin{array}{l}\text { Ambas autoridades son nombrados } \\
\text { por el PEN a propuesta de la } \\
\text { Secretaría deObras Públicas }\end{array}$ \\
\hline $\begin{array}{l}\text { Estabilidad en sus } \\
\text { funciones }\end{array}$ & No tiene & No tiene & No tiene \\
\hline $\begin{array}{l}\text { Controles sobre el } \\
\text { organismo }\end{array}$ & AGN SIGEN & $\begin{array}{l}\text { AGN, SIGEN el COngreso } \\
\text { (principalmente por la Comisión } \\
\text { Bicameral de Seguimiento de las } \\
\text { Privatizaciones) }\end{array}$ & $\begin{array}{l}\text { AGN, SIGEN el Congreso } \\
\text { (principalmente por la Comisión } \\
\text { Bicameral de Seguimiento de las } \\
\text { Privatizaciones) }\end{array}$ \\
\hline Financiamiento & Presupuesto Nacional & $\begin{array}{l}\text { Presupuesto Nacional a través } \\
\text { de la DNV }\end{array}$ & $\begin{array}{l}0,5 \% \text { Recaudación neta de peaje } \\
1 \% \text { por explotación de areas de } \\
\text { servicio, redondeo de la tarifa de } \\
\text { peaje al público. }\end{array}$ \\
\hline
\end{tabular}

Fuente: Elaboración propia en base a información de los organismos.

\footnotetext{
* En el proceso de reconversión vial, se interviene la DNV, se organiza la transferencia provincial y la concesión de rutas. A través de ese y otros decretos y resoluciones se otorgan atribuciones de regulación a la DNV. ** En la primera etapa del organismo (hasta noviembre de 2003) fue responsable por 18 corredores viales. Posteriormente, a partir de la concesión producida en 2003 el organismo pasó a ser responsable de la regulación de 8 corredores viales (6 concesionados en 2003 más 2 que provenían del proceso anterior)
} 
La secuencia ideal para las concesiones y privatizaciones indica que, antes de llevar adelante las concesiones, se elabore el marco regulador y se ponga en funciones el organismo regulador. Este no es el caso de los corredores viales concesionados, en 1990, donde el procedimiento se encuentra completamente alterado. Al momento de la segunda concesión, ya existía una institución reguladora y una experiencia previa de regulación pero la inestabilidad institucional previa y la escasa transparencia del sector parecen no haber resultado suficiente incentivo para que las nuevas concesiones se realizaran luego de la elaboración de un marco de regulación consensuado. En 2003 la licitación se resuelve en el Poder Ejecutivo.

FIGURA 1: Comparación de secuencias de concesión de redes viales.

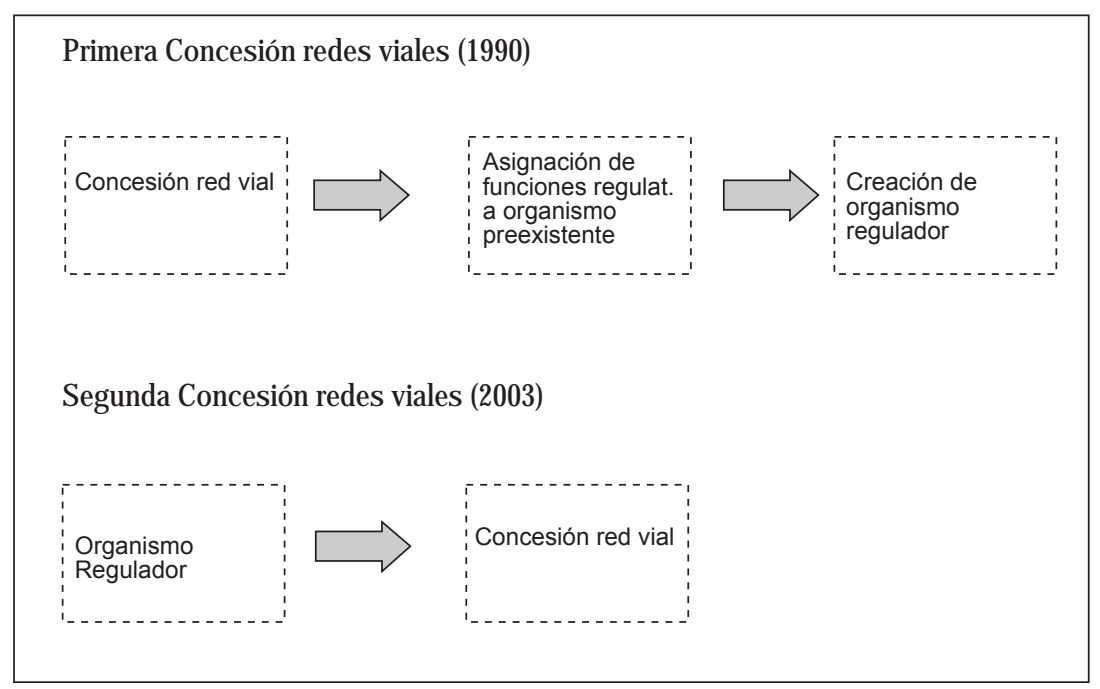

Fuente: Elaboración propia

A pesar de la preexistencia del organismo regulador, la Autoridad de Aplicación fue delegada al Ministerio de Planificación (y la Secretaria de Obras Públicas). Así, el Ministerio fue responsable de realizar el llamado a licitación; aprobar los pliegos de condiciones y demás documentación para la realización de la licitación y organizar la Comisión de Concesiones para la consecución y seguimiento del llamado. No obstante, dicha Comisión fue presidida por el Director Ejecutivo del OCCOVI y participaron representantes de la DNV entre otras áreas.

25 No obstante, debe considerarse que en el 2003 sólo se concesiona parte de la red vial pues producto de la etapa anterior persistían dos contratos (CV 18 y CV 29). 
Por otra parte, se espera que un marco de regulación establecido en el debate parlamentario aumente las probabilidades de consolidación de una agencia reguladora con mayor legitimidad y continuidad en sus funciones pero ni el OCCOVI ni sus antecesores han sido creados por una ley. En tanto, a fin de fortalecer la autonomía de estos organismos es menester que el marco de regulación contenga normas claras, sencillas y coherentes reunidas en un cuerpo único. Tal como fue señalado en el sector existió una superposición de normas.

En materia presupuestaria, corresponde señalar que el organismo cuenta con recursos propios, integrados por el 0,5\% sobre la recaudación neta de peaje, $1 \%$ sobre el producido por explotación de áreas de servicio y el redondeo de la tarifa de peaje al público (Oficina Nacional de Presupuesto). Desde 2003, el organismo logró incrementar su presupuesto con un salto de recursos ${ }^{26}$. En tal sentido, en 2007, se reasignaron para el pago de obras viales que se encontraban en construcción $\$ 50.000 .000$ que se sumaban a las asignaciones presupuestarias y a los Fondos del Sistema Integrado de Transporte (SIT). En definitiva, el organismo de control que administraba alrededor de $\$ 6.000 .000$, con el anterior modelo de concesión, pasó a administrar fondos por más de $\$ 93.000 .000$, en 2005 , y de $\$ 246.000 .000$, en 2006. Sin embargo, como se demostró estos aspectos no tuvieron impacto sobre la capacidad del organismo para fiscalizar las rutas nacionales concesionadas.

En el cuadro que se presenta a continuación se plantean los distintos criterios que definen el grado de autonomía del diseño institucional de un organismo regulador ${ }^{27}$. En cada uno de los criterios se establecieron las características que tendría un diseño tendiente a incrementar el nivel de autonomía y transparencia de la agencia reguladora.

Si para cada uno de los criterios indicados en el cuadro 6 se otorgara 1 punto a los diseños que resguardan un mayor nivel de autonomía, un 0 para los organismos cuyas características coinciden con las que se definen como de un menor nivel de autonomía y un 0,5 para los que tienen algún nivel intermedio, un diseño de alta autonomía arrojaría una evaluación igual a 10 puntos. Sin embargo, la evaluación del diseño del OCCOVI arroja un resultado que apenas alcanza un punto, debido a que la baja autonomía que no pudo ser revertida en la práctica institucional, sobre la que profundizaremos en la siguiente sección ${ }^{28}$.

26 La ley 26.198 de presupuesto habilita al Jefe de Gabinete a modificar el destino de las partidas presupuestarias, sin una intervención previa del Congreso.

27 La evaluación del grado de autonomía del organismo se ha realizado siguiendo el modelo propuesto por Melo y Gaetani (2005).

28 Se asigna un valor medio en materia presupuestaria debido a que los fondos del organismo se recaudaban internamente pero luego se transferían a la cuenta del Tesoro Nacional. 
TABLA 5: Autonomía y transparencia en el diseño del organismo regulador.

\begin{tabular}{|c|c|c|}
\hline \multirow{2}{*}{ Criterio } & \multicolumn{2}{|c|}{ Grado de autonomia esperado } \\
\hline & Mayor & \\
\hline \multicolumn{3}{|c|}{ I. Autonomía del organismo (medido fundamentalmente en relación con la presión política) } \\
\hline $\begin{array}{l}\text { Nombramiento del Director } \\
\text { Ejecutivo }\end{array}$ & $\begin{array}{l}\text { Intervención del Poder Legislativo u otras instancias } \\
\text { deliberativas. }\end{array}$ & Exclusiva participación del Poder Ejecutivo. \\
\hline $\begin{array}{l}\text { Reemplazo del Director } \\
\text { Ejecutivo }\end{array}$ & $\begin{array}{l}\text { Establecido por la normativa (periodicidad pautada, } \\
\text { por decisión del legislativo) }\end{array}$ & Estabilidad sujeta a la decisión del Poder Ejecutivo. \\
\hline Presupuesto & $\begin{array}{l}\text { Presupuesto pautado por el organismo, en función } \\
\text { de fondos propios. }\end{array}$ & $\begin{array}{l}\text { Interferencia del Poder Ejecutivo en el presupuesto } \\
\text { del organismo. Los Fondos son transferidos desde } \\
\text { la cuenta única (aún cuando en algunos casos } \\
\text { puedan ser recursos propios) }\end{array}$ \\
\hline $\begin{array}{l}\text { Profesionalización de los } \\
\text { funcionarios }\end{array}$ & $\begin{array}{l}\text { Alto nivel de profesionalización y especialización en } \\
\text { el área de regulación y del sector en particular. }\end{array}$ & Bajo nivel de profesionalización \\
\hline $\begin{array}{l}\text { Autorización de cambios en } \\
\text { la conformación de } \\
\text { concesionarios }\end{array}$ & Organismo regulador & Poder Ejecutivo, administración central. \\
\hline $\begin{array}{l}\text { Definición y aprobación de la } \\
\text { tarifa }\end{array}$ & Organismo regulador. & Poder Ejecutivo, administración central. \\
\hline $\begin{array}{l}\text { Poder de veto sobre } \\
\text { decisiones regulatorias }\end{array}$ & $\begin{array}{l}\text { Sin poder de veto del poder ejecutivo, aunque se } \\
\text { den instancias de control. Fundamentalmente, } \\
\text { revisión legislativa. }\end{array}$ & $\begin{array}{l}\text { Amplía capacidad de veto de las decisiones } \\
\text { regulatorias desde el Ejecutivo. }\end{array}$ \\
\hline \multicolumn{3}{|c|}{ II. Transparencia del diseño institucional } \\
\hline Marco regulatorio & $\begin{array}{l}\text { Existencia de una ley que establezca los objetivos } \\
\text { y funciones del organismo regulador. }\end{array}$ & $\begin{array}{l}\text { Dispersión de normas que establecen objetivos y } \\
\text { funciones del organismo regulador. }\end{array}$ \\
\hline $\begin{array}{l}\text { Responsabilidad frente a la } \\
\text { administración central }\end{array}$ & $\begin{array}{l}\text { Específicamente establecida por ley una } \\
\text { responsabilidad univoca hacia un Ministerio o } \\
\text { Secretaría de Estado. }\end{array}$ & $\begin{array}{l}\text { No fijada por la normativa de creación del organismo. } \\
\text { Maleable. }\end{array}$ \\
\hline Control social & $\begin{array}{l}\text { Obligación de presentar informes periodicos de } \\
\text { gestión, publicitar sus decisiones y brindar información } \\
\text { pública. }\end{array}$ & $\begin{array}{l}\text { Sin obligación de brindar información sobre la } \\
\text { actividad del organismo. }\end{array}$ \\
\hline
\end{tabular}

Fuente: Elaboración propia. Los criterios han sido elaborados en base a Melo y Gaetani (2005) y Serafinoff (2003). Sin embargo, las alternativas y especificaciones graduales se han establecido en función de esos y otros trabajos que componen el marco teórico.

A partir de la misión del organismo, los objetivos y funciones asignadas a través de la normativa de creación, el OCCOVI se constituye como un organismo abierto a vínculos e interrelaciones, principalmente, con organismos del Gobierno Nacional, pero también del ámbito subnacional (organismos provinciales y municipales). Por otra parte, las funciones que se especifican como responsabilidad del organismo genera espacios para estrechar vínculos con cámaras, asociaciones y demás organizaciones de la sociedad civil (ver Figura 2).

Para la identificación de los vínculos entre los organismos identificados en el mapa se han considerado, exclusivamente, los lazos de relación en el sector de las rutas nacionales concesionadas. Por ello, no se ha graficado, por ejemplo, el rol de la DNV en cuanto a la preservación de la calzada y mantenimiento de las rutas. Por otra parte, se ha decidido incluir en el gráfico las relaciones entre organismos (incluso si la interacción no se produce, en forma 
paralela, con el OCCOVI). Esta decisión tiene su fundamento en que la situación real observada muestra una débil participación del organismo en el sector, la cual, a diferencia de lo que ocurre en muchos otros sectores, también surge del análisis de la situación formalmente aprobada. Por ello, al captar a través del gráfico estos vínculos se intenta tener un mapa más acabado de las interacciones asociadas a la concesión de redes viales. No obstante, se podrá observar que se han privilegiado las relaciones de los distintos organismos con el OCCOVI.

Los trece tipos de interacciones que se indican ${ }^{29}$ podrían reducirse a cinco, si se consideran con un mayor nivel de agregación:

- Mantenimiento de los caminos y cobro de peajes: asociada a la prestación de un servicio vinculado con el bien público que representan los caminos concesionados.

- Auditoria, regulación y control de los concesionarios y las obras realizados: referida a la realización de controles técnico-ambientales, de legalidad y económico-financiero sobre los concesionarios, pero también el control sobre la contratación de terceros para la realización de obras públicas en las rutas concesionadas.

- Contratación de terceros: referido a los contratos de asistencia técnica y asesoramiento y al llamado a licitaciones para realizar obras que son competencia del estado en los caminos concesionados.

- Supervisión y control del organismo: asociadas con el control interno y externo sobre el OCCOVI y las acciones de rendición de cuentas por las acciones y decisiones tomadas. Dentro de esta categoría también se consideran las interacciones vinculadas con la supervisión general o la dependencia jerárquica (cuando se trata de organismos de la administración central)

- Intercambio de información: referido a las interacciones que involucran la obligación de entregar información (v.g. estados contables, composición accionaria en el caso de los concesionarios), así como el intercambio entre organismos que cumplen funciones complementarias.

Entre los organismos estatales que desempeñan las funciones más medulares vinculadas con la regulación de las concesiones viales y el mantenimiento de los caminos se encuentran la Secretaría de Obras Públicas, la Subsecretaría de Obras Públicas, la DNV y el OCCOVI. Las funciones que formalmente desempeñan cada uno de estos organismos en relación con la temática de interés demuestran la fragmentación de las funciones y la necesidad de establecer

29 Si el mapa recogiera la información referida a las interacciones que se producían en la etapa anterior de concesiones debería haberse incluido una interacción asociada con los ajustes tarifarios. No era el OCCOVI (ni los organismos que lo antecedieron en las funciones de control) sino la Secretaría de Obras Públicas y el Ministerio de Economía (o Infraestructura, según el período) quien habilitaba o impedía dichos ajustes. A partir del nuevo modelo de concesiones viales, el contrato fija que deben producirse determinadas condiciones para que se produzcan ajustes tarifarios y que los mencionados ajustes pueden darse a solicitud de los concesionarios y/o el OCCOVI. 
fuertes mecanismos de coordinación para poder llevar adelante las tareas que les fueron asignadas en forma efectiva ${ }^{30}$. Si en lugar de considerar la misión y responsabilidades a partir de la estructura organizativa de cada una de las instituciones se consideran las responsabilidades asignadas en los contratos de concesión se amplía, notablemente el número de las funciones específicas y la complejidad del entramado.

FIGURA 2: Mapa de relaciones interinstitucionales del OCCOVI, asociado a las rutas nacionales concesionadas.

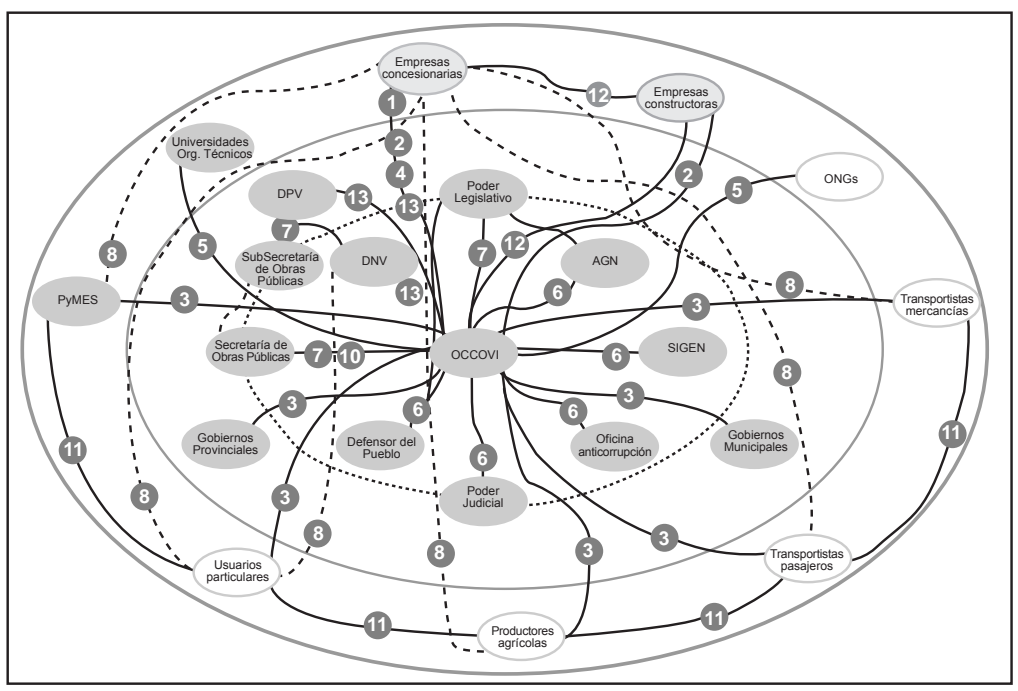

1. Controla el cumplimiento de los contratos de concesión y aplica sanciones.

2. Controla la obra pública realizadas en jurisdicción de los contratos de concesión

3. Recibe solicitudes y requerimientos

4. Recibe propuestas de explotación complementarias

5. Recibe asistencia técnica

6. Es controlado

7. Es supervisado en su funcionamiento

8. Dependencia jerárquica, administración central

9. Cuida el estado del pavimento, realiza tareas de mantenimiento y cobra peaje

10. Asesora en los procesos licitatorios de obra pública

11. Conforman asociaciones para realizar estudios sobre las concesiones y presentar reclamos

12. Contrata para la realización de obras en caminos concesionados

13. Intercambio de información.

Fuente: Elaboración propia.

30 A estas funciones habría que incorporar, por ejemplo, la de "Coordinar la elaboración de políticas y ejecución de acciones en materia de seguridad vial" que es asignada a la Secretaría de Transporte. 
Así como se observa una estrecha relación entre la Secretaría de Obras Públicas y el OCCOVI, existe una marcada desvinculación entre la DNV y el OCCOVI. Ambos organismos no mantienen interacciones en forma constante, aún cuando sus funciones están fuertemente asociadas. Uno de los mejores indicadores de la falta de coordinación de actividades realizadas por estos dos descentralizados se observa en que el OCCOVI no cuenta con información sobre la regulación de las redes viales de los primeros años de la concesión, mientras que en las oficinas de la DNV no se observa información sobre el nivel de tránsito o estado de los caminos en los tramos concesionados desde que entrara en funciones el OCCOVI. La relación entre el regulador y los organismos con atribuciones en el campo vial es crucial. Resulta importante la coherencia entre los objetivos y políticas de ambas instancias y la racionalidad de la división del trabajo entre ellas (López y Forcinito, 2005).

\section{Conclusiones}

Cuando las necesidades específicas de la infraestructura concesionada no se identifican en forma previa, las fallas regulatorias se hacen más evidentes. La menor diagramación y estudio de las condiciones iniciales y los riesgos existentes aumenta la asimetría en desmedro de la posición de los usuarios y la ciudadanía. Estas falencias iniciales se vuelven muy difíciles de revertir.

La vertiginosa concesión de caminos y la uniformidad temporal del proceso de licitación favorecieron la opacidad del proceso y el comportamiento colusivo. En tal sentido, un proceso de concesiones progresivo y realizado en distintos momentos permite realizar un estudio más profundo sobre las condiciones de las obras a concesionar. Así, la competitividad de las licitaciones puede ampliarse cuando existe una programación de licitaciones que permite, por ejemplo, que empresas de menor tamaño puedan afrontar los costos de presentarse en la licitación.

Respecto de la resolución de dichos procesos de licitación, se observa que si bien la tarifa y el canon propuestos son criterios importantes para definir las concesiones, no pueden ser los únicos. La ausencia de estudios sobre las probabilidades de cumplir con las obras presentadas por los consorcios generó consecuencias irreparables. Esta situación nos lleva a concluir que los llamados a licitación deben efectuarse sobre la base de proyectos definitivos y sustentados en informes técnicos actualizados. De forma que puedan recortarse las posibilidades de modificación de obra y variaciones presupuestarias. En la segunda licitación de rutas nacionales podría haberse contado con dicha información. No obstante, la premura con la que se llevó adelante el proceso generó que las condiciones para que esta cuestión volviera a ser desplazada de la escena.

A pesar de las similitudes que pueden encontrarse en ambos procesos de concesión de redes viales, es de destacar que las características del modelo de concesión/regulación creado 
en 1989 genera déficit de capacidades más difíciles de revertir que las del segundo modelo. El diseño institucional creado en 2003 tiene un menor impacto sobre el desempeño del sector puesto que, como se analizó a lo largo del trabajo, son las licitaciones de los tramos para reparación y mejora de los caminos las que pasan a ocupar un lugar centra| ${ }^{31}$.

Otro de los puntos que facilita la transparencia es la existencia de un marco regulatorio único. La alta dispersión normativa que caracterizó al sector favoreció la vulnerabilidad. En tal sentido, se considera que la claridad de las reglas y la credibilidad de las instituciones tienen un importante papel en la reducción de los riesgos regulatorios. Así, el primer modelo de concesiones estuvo signado por la incapacidad (o falta de voluntad) para llevar adelante acuerdos que establecieran claridad y transparencia al vínculo entre los concesionarios viales y el Estado. Sin embargo, la incertidumbre que caracterizó la primera de las concesiones viales no fue neutral, ya que afectó de distinta forma a los actores involucrados y benefició a los concesionarios. La estabilidad de las normas que enmarcaron el segundo período de concesiones viales es mayor, pues no se observaron renegociaciones ni reformas amplias en los acuerdos iniciales. Sin embargo, la fragmentación normativa persistió por la ausencia de una marco regulatorio único.

A lo largo del trabajo, se han observado los continuos cambios respecto de la responsabilidad de controlar las redes viales concesionadas. Distintos organismos se sucedieron orientándose, al menos formalmente, al cumplimiento de dicha misión. A pesar de las distintas cristalizaciones burocráticas, los distintos organismos responsables del control de las redes viales conservan un elemento común que es su baja autonomía. Así, se ha podido observar que, con mayores o menores recursos, la agencia de control se ha caracterizado por el bajo grado de libertad para cumplir con sus objetivos. Esta capacidad, como señalamos anteriormente, se caracteriza por el sesgo que imponen: el gobierno y los empresarios.

El estudio del caso de las concesiones viales de las rutas argentinas y la relación entre el Estado y los empresarios del sector sirve para sostener la proposición que señala que las oposiciones de los actores sociales en y a través del Estado contribuyen al debilitamiento de un marco social e institucional ya débil pues los distintos actores de la sociedad civil pugnan por insertar directamente sus intereses de grupo en el Estado.

Analizar el rol del Estado como regulador nos permite profundizar en el conocimiento de la forma en que el Estado actúa, se interrelaciona con otros actores y se expresa a través de políticas públicas. A lo largo del trabajo se ha demostrado que la concesión de redes viales y

31 En relación con el comportamiento empresario, es de destacar que es en esas licitaciones donde se verifica la concentración empresarial, reproduciéndose el modelo de la patria contratista. 
su regulación no es un hecho aislado, por ello, se espera que el artículo haya resultado relevante como indicador de las condiciones en las que el Estado se expresa y la forma en que lo hace a partir de sus interacciones con otros actores, pero también es resultante de las capacidades estatales. 


\section{Referencias Bibliográficas}

AGN - Auditoría General de la Nación. 2006. Informe de Auditoría sobre concesiones viales. Buenos Aires: AGN.

Azpiazu, D. 2002. Privatizaciones y Poder Económico. Buenos Aires: FLACSO, IDEP, Ediciones Universidad Nacional de Quilmes.

Azpiazu, D. y J. Pesce. 2003. La Privatización del Sistema Vial en la Argentina ¿Errores de Diseño o Desmedidos Privilegios para una Fracción del Poder Económico Local? Documento de Trabajo FLACSO 11. Buenos Aires: FLACSO.

Bousquet, F. y A. Fayard. 2001. Road Infrastructure Concession Practice in Europe. World Bank Policy Research Working Paper 2675. Cambridge: World Bank. Cordero Vargas, R. 1999. El Rol Regulador del Estado en Obras Viales Concesionadas. Estudio de Caso 35. Santiago: Universidad de Chile, Departamento de Ingeniería Industrial, Magister en Gestión y Políticas Públicas.

Davis, E. y S. Flanders. 1995. Conflicting Regulator Objectives: The Supply of Gas to UK Industry. En The Regulatory Challenge, editado por Bishop, M., J. Kay y C. Mayer, 43-66. Nueva York: Oxford University Press.

Delgado, R. 1998. Inversiones en Infraestructura Vial: la Experiencia Argentina. Serie Reformas Económicas CEPAL 6. Santiago: CEPAL.

Estache, A. y G. de Rus. 2000. Privatización y Regulación de Infraestructura de Transporte. Una guía para Reguladores. Washington: Banco Mundial, Alfaomega. Estache, A., M. Romero y J. Strong. 2000. Carreteras de Peaje. En Privatización y Regulación de Infraestructura de Transporte. Una guía para Reguladores, editado por Estache, A. y G. de Rus. Washington: Banco Mundial, Alfaomega.

FIEL. 1998. La regulación de la Competencia y de los Servicios Públicos. Teoría y Experiencia Argentina Reciente. Buenos Aires: FIEL.

Gerchunoff, P. y G. Canovas. 1994. Las privatizaciones en Argentina: Impactos Micro y Macroeconómicos. Serie Reforma de Políticas Públicas 21 Santiago: CEPAL- Gobierno de Países Bajos- PNUD.

Gómez-lbáñez, J. 2003. Regulating Infraestructure. Monopoly, Contracts and Discretion. Cambridge: Harvard University Press.

Gómez-Lobo, A. y S. Hinojosa. 1999. Broad Roads in a Thin Country. Infrastructure Concessions in Chile. World Bank Policy Research Working Paper 2279. Cambridge: World Bank.

Llanos, M. y A. Margheritis. 1999. Liderazgo Presidencial y Dinámica Institucional durante la Primera Presidencia de Menem. Política y Gobierno VI (2): 441-475. Melo, M. y F. Gaetani. 2005. Capacidades Estatales: Agencias de Regulación y Control. Ponencia presentada en el X Congreso Internacional del CLAD sobre la Reforma del Estado y de la Administración Pública, 8- 11 de Octubre de 2002, Lisboa, Portugal. Oszlak, Oscar.1999. De Menor a Mejor: El Desafío de la 'Segunda' Reforma del Estado. Nueva Sociedad 160: 81-100.

Rima, J.C., J. Sánchez y L. Yánez. 1997. La Vialidad Argentina y la Concesión por Peaje en Rutas Nacionales. Antecedentes y Evaluación de los Primeros Siete Años de Concesión. Serie de Estudios CECE 25. Buenos Aires: CECE.

Rufián Lizano, D. 2002. Políticas de Concesión Vial: Análisis de las Experiencias de Chile, Colombia y Perú. Serie Gestión Pública 16. Santiago: Proyecto ILPES/ CAF "Marco Regulatorio, privatización y modernización del Estado". 
Serafinoff, V. 2003. La Regulación de los Servicios Públicos Privatizados: ¿una Cuestión Problematizada?. Revista Realidad Económica 194: 103-124.

Valeria Serafinoff es investigadora del Área Política y Gestión Pública del Centro de Estudios de Estado y Sociedad (CEDES), Argentina. Es Maestra de Administración Pública por la Universidad de Buenos Aires y Licenciada en Ciencia Política por la Universidad del Salvador. Actualmente cursa el Doctorado en Ciencia Política de la Escuela de Política y Gobierno de la Universidad Nacional de San Martín.

E-Mail: vserafinoff@cedes.org 